\title{
A new skull of an early diverging rorqual (Balaenopteridae, Mysticeti, Cetacea) from the late Miocene to early Pliocene of Yamagata, northeastern Japan
}

\author{
Yoshihiro Tanaka, Kazuo Nagasawa, and Yojiro Taketani
}

\begin{abstract}
The family of rorquals and humpback whales, Balaenopteridae includes the largest living animal on Earth, the blue whale Balaenoptera musculus. Many new taxa have been named, but not many from the western Pacific, except Miobalaenoptera numataensis from Japan. Here we describe an early balaenopterid, cf. M. numataensis from a late Miocene to early Pliocene sediment in Yamagata Prefecture, northeastern Japan. The species has a straight and sharp lateral ridge of the fovea epitubaria at the ventral surface of the periotic, and a dorsoventrally thin pars cochlearis. The new specimen provides knowledge of supposed ontogenetic variation and periotic morphology in poorly known fossil balaenopterids.
\end{abstract}

Yoshihiro Tanaka. Osaka Museum of Natural History, Nagai Park 1-23, Higashi-Sumiyoshi-ku, Osaka, 5460034, Japan. tanaka@mus-nh.city.osaka.jp

Hokkaido University Museum, Kita 10, Nishi 8, Kita-ku, Sapporo, Hokkaido 060-0810 Japan, Numata Fossil Museum, 2-7-49, Minami 1, Numata town, Hokkaido 078-2225 Japan

Kazuo Nagasawa. Yamagata Prefectural Touohgakkan Junior and Senior High School. 1-7-1 ChuoMinami, Higashine City, Yamagata Prefecture, Japan 999-3730. snagasawak@pref-yamagata.ed.jp Yojiro Taketani. Aizuwakamatsu City, Fukushima Prefecture, Japan. yojirotak.11-22@sa2.so-net.ne.jp

Keywords: rorquals; Balaenopteridae; Noguchi Formation; Furukuchi Formation; Miobalaenoptera numataensis; ontogenetic variation

Submission: 25 May 2019. Acceptance: 20 February 2020.

\section{INTRODUCTION}

The family of rorquals and humpback whales, Balaenopteridae includes the largest living animal on Earth, the blue whale Balaenoptera musculus. Many new taxa have been named from Europe
(Van Beneden, 1880; Strobel, 1881; Sacco, 1890; Bisconti, 2007a, 2007b, 2010; Bosselaers and Post, 2010; Bisconti and Bosselaers, 2016) and the East Coast of the U.S. (Whitmore and Kaltenbach, 2008). The Pacific also provides many of

Tanaka, Yoshihiro, Nagasawa, Kazuo, and Taketani, Yojiro. 2020. A new skull of an early diverging rorqual (Balaenopteridae, Mysticeti, Cetacea) from the late Miocene to early Pliocene of Yamagata, northeastern Japan. Palaeontologia Electronica, $23(1)$ :a12. https://doi.org/10.26879/1002

palaeo-electronica.org/content/2020/2943-fossil-rorqual-from-japan

Copyright: March 2020 Society of Vertebrate Paleontology.

This is an open access article distributed under the terms of the Creative Commons Attribution License,

which permits unrestricted use, distribution, and reproduction in any medium, provided the original author and source are credited.

creativecommons.org/licenses/by/4.0 
nominal species (Cope, 1872; Kellogg, 1922; Hanna and McLellan, 1924; Dathe, 1983; Deméré, 1986; Pilleri, 1989; Zeigler et al., 1997; Boessenecker, 2013; Marx and Kohno, 2016), but most of them are known from the eastern Pacific, except Miobalaenoptera numataensis from Japan (Tanaka and Watanabe, 2019a). From Japan, some unnamed balaenopterids were published, such as several Balaenopteridae indet. from Miocene sediments (Nagasawa, 1995; Hasegawa et al., 2002; Kohno et al., 2007; Sato et al., 2010; Kimura et al., 2015), and several Burtinopsis sp. (Hatai et al., 1963; Oishi et al., 1985; Oishi, 1988, see also Oishi and Hasegawa, 1995a), aff. Balaenoptera borealis (Hasegawa et al., 1988), two "Megaptera" sp. (Oishi and Hasegawa, 1995b, Nagasawa, 1999, see also Ichishima, 2005), Balaenoptera sp. (Oishi, 1994), Sibbaldus sp. (Oishi, 1997) and several Balaenopteridae indet. (Oishi, 1987; Iwaki Educational and Cultural Corporation. 1989; Oishi and Hasegawa, 1995b; Kimura and Kanaya, 1996; Nagasawa, 1999) from Neogene sediments.

Our knowledge on the ontogenetic variation among fossil cetaceans is still limited (Tanaka and Watanabe, 2019b). There are many extant cetacean ontogeny studies (Kasuya, 1973; Perrin, 1975; Ito and Miyazaki, 1990; Bisconti, 2001; Galatius and Kinze, 2003; de Buffrénil et al., 2004; Kurihara and Oda, 2009; Chen et al., 2011; Galatius et al., 2011; Walsh and Berta, 2011; Cozzi et al., 2012, 2015; Nakamura et al., 2012; Nakamura and Kato, 2014; Tsai and Fordyce, 2014; Hampe et al., 2015; Moran et al., 2015). But, the number of reports on fossil cetacean ontogeny is still limited (Uhen, 2004; Gutstein et al., 2009; El Adli et al., 2014; Boessenecker and Fordyce, 2015; Tanaka, 2016; Tanaka and Ichishima, 2016; Tanaka and Watanabe, 2019b). Here we describe an early member of the family Balaenopteridae: cf. Miobalaenoptera numataensis from a late Miocene to early Pliocene sediment in Yamagata Prefecture, Japan providing additional insight into the ontogenetic variation and periotic morphology of extinct balaenopterids.

\section{MATERIAL AND METHODS}

We follow the anatomical terms of Mead and Fordyce (2009) for the skull and periotic.

Abbreviations. NFL, Numata Fossil Museum, Numata Town, Hokkaido, Japan; USNM, Department of Paleobiology, National Museum of Natural History, Smithsonian Institution, Washington, D.C., USA; YPM, Yamagata Prefectural Museum, Japan.
Referred specimen. YPM 11851 includes the skull (parietal, alisphenoid, pterygoid, squamosal, exoccipital, basioccipital, supraoccipital, fused presphenoid and basisphenoid) and periotics in situ. The specimen was collected by Sadao Ito and Kazuo Nagasawa in 1992.

Locality. YPM 11851 was found as a float at the Akamatsu River in Ōkura Village, Yamagata Prefecture, Japan. The site is about $10 \mathrm{~km}$ south from the main residential area of the village (Figure 1): latitude $38^{\circ} 35^{\prime} 13.8^{\prime \prime} \mathrm{N}$, longitude $140^{\circ} 13^{\prime} 03.2^{\prime \prime} \mathrm{E}$.

Horizon and age. The matrix of YPM 11851 is light gray tuffaceous sandstone with sea shell fragments. At the locality of YPM 11851 and the upper stream of the Akamatsu River, two sedimentary rocks (the Noguchi and Furukuchi Formations) are exposed (Tamiya and Applied Geological Society of Yamagata, 2016). Depositional facies of these formations are varied among each formation, and it is difficult to identify the original formation based on facies. Thus, both the Noguchi and Furukuchi Formations could be the original horizon for YPM 11851. Microfossils (planktonic foraminiferas and radiolarians) were searched from the matrix of YPM 11851 for the age assignment, but they could not be found. The ages of the Noguchi and Furukuchi Formations are from the late Miocene to early Pliocene (Moriya et al., 2008; Tamiya and Applied Geological Society of Yamagata, 2016). From the Akamatsu River near the locality, whale mandibles and a rib (Nagasawa et al., 2002), a vertebra (Nagasawa, 1993), and a sperm whale tooth (Nagasawa et al., 2009) were reported.

\section{SYSTEMATIC PALEONTOLOGY}

\author{
Order CETACEA Brisson, 1762 \\ Unranked taxon NEOCETI Fordyce and de \\ Muizon, 2001 \\ Suborder MYSTICETI Gray, 1864 \\ Family BALAENOPTERIDAE Gray, 1864 \\ cf. Miobalaenoptera numataensis Tanaka and \\ Watanabe, 2019 \\ (Figures 2-5, Tables 1 and 2)
}

Remarks. YPM 11851 is comparable to Miobalaenoptera numataensis by having similarities such a straight and sharp lateral ridge of the fovea epitubaria (Character 273 in this study, see discussion), a dorsoventrally thin pars cochlearis, a straight and horizontally expanded subtemporal crest of the squamosal, and strongly posterolaterally diverged basioccipital crest, which were used as diagnoses for $M$. numataensis in Tanaka and Watanabe (2019a). In this study, YPM 11851 is 


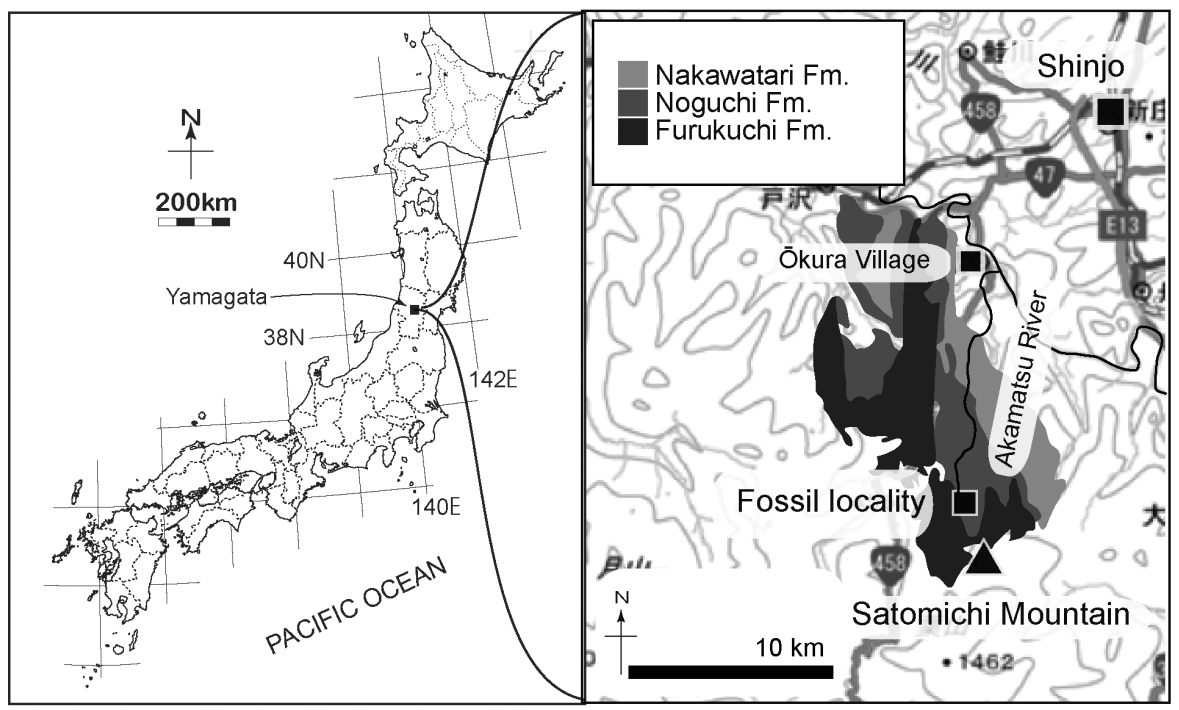

FIGURE 1. Maps showing the locality of cf. Miobalaenoptera numataensis (YPM 11851). The base map of the right one is from the online topographic maps published by the Geospatial Information Authority of Japan. The distribution of formations follows Tamiya and Applied Geological Society of Yamagata (2016).

identified as cf. M. numataensis preliminary, because there are several differences from the holotype of $M$. numataensis (see discussion and also Table 3). It cannot be identified as the species because of limited knowledge on ontogenetic and other variations of the species.

Emended diagnoses for Miobalaenoptera numataensis. Minor emendation including an identification of the lateral ridge of the fovea epitubaria and adding measurements is made here. Among the Balaenopteridae, Miobalaenoptera numataensis uniquely has the lateral ridge of the fovea epitubaria, which is straight and sharp, running to the anterior pedicle of the ventral surface of the periotic (see discussion). The ridge is located more anterior than that of the modern balaenopterids. $M$. numataensis also uniquely has a dorsoventrally thin pars cochleais (especially medial edge). The medial edge of the pars cochlearis is thinner than the diameter of the internal acoustic meatus $(9.1 \mathrm{~mm}$ thick and $12.1 \mathrm{~mm}$ in diameter, respectively, on the holotype). Tanaka and Watanabe (2019a) mentioned differences with other balaenopterids as below. M. numataensis is different from other balaenopterids except "Balaenoptera" ryani by a feature, an incipient lateral tuberosities of the periotic. M. numataensis is different from other balaenopterids except "Megaptera" miocaena, Protororquals cuvieri, and Megaptera novaeangliae by features, a slender zygomatic process, and a strongly excavated lateral margin of the orbit in dorsoventral view. $M$. numataensis is different from other balaenopterids except Fragilicetus velponi by a feature, strongly diverged basioccipital crests. $M$. numataensis is different from the other extinct balaenopterids except "Megaptera" hubachi by a feature, a broadly or more or less horizontally expanded subtemporal crest. $M$. numataensis is different from the extant taxa and "Megaptera" miocaena by a feature, a deep suprameatal fossa of the periotic. M. numataensis is different from the extinct taxa except Fragilicetus velponi by a feature, a long caudal tympanic process of the periotic. Here, we add differences between $M$. numataensis and supposed closely related Incakujira anillodefuego. M. numataensis is different from $I$. anillodefuego and also Diunatans luctoratemergo by some features, higher basioccipital crests, and straight subtemporal crest in ventral view. M. numataensis is different from $I$. anillodefuego by several features such as, a more anteriorly located foramen pseudovale, a strongly excavated orbit in dorsoventral view, more robust zygomatic process, larger postorbital process in lateral view, straight ventral margin of the anterior tip of the zygomatic process, a more slender caudal process of the periotic, and deeper area lateral from the fenestra rotunda and dorsal from the posteroventral margin of the pars cochlearis. $M$. numataensis is different from $D$. luctoratemergo by several features such as, more laterally projected basioccipital crest, a blunt anterior tip of the anterior process of the periotic in mediolateral view, dorsoventrally thinner and more flat pars cochlearis. 


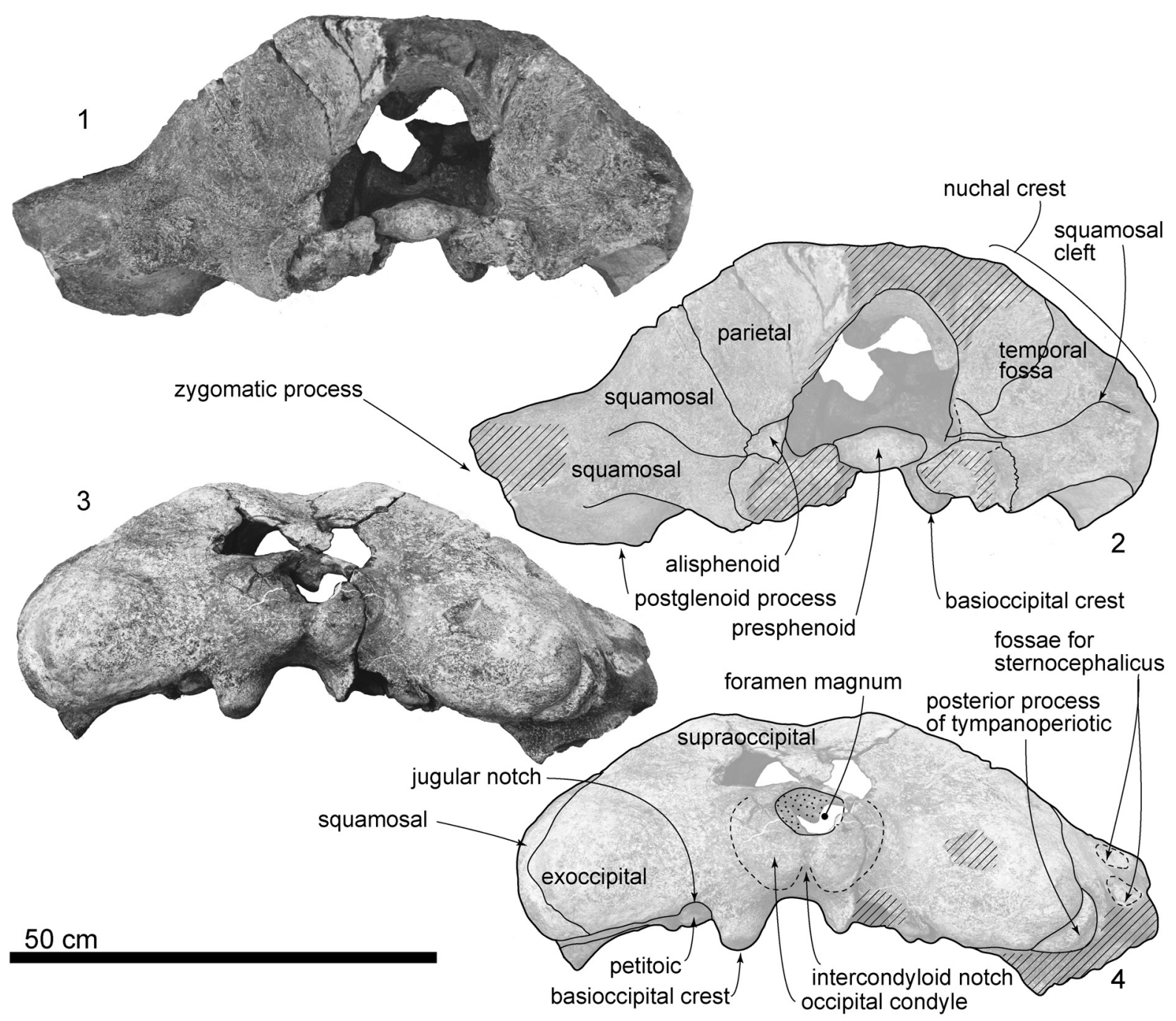

FIGURE 2. 1-4, Skull of cf. Miobalaenoptera numataensis (YPM 11851) in anterior view (1, 2), posterior view (3, 4), photos $(1,3)$, line drawings $(2,4)$.

\section{GENERAL DESCRIPTION}

Ontogeny. YPM 11851 shows clear sutures between the squamosal/parietal, squamosal/pterygoid, and exoccipital/squamosal. The suture between squamosal/pterygoid is closed, but still visible. The joint between the basioccipital/exoccipital, and exoccipital/supraoccipital are closed completely. The basioccipital and basisphenoid border is closed, but still visible. The presphenoid and basisphenoid border is closed completely. All of extant mysticete show the same sequence of ossification from the joints of the basioccipital/exoccipital firstly, basioccipital/basisphenoid secondly, and the supraoccipital/exoccipital finally (Walsh and Berta, 2011). The ontogenetic stage of YPM 11851 is not certain, but is thought to be juvenile based on opened joints as mentioned above, and not a calf based on the fused supraoccipital/exoccipital joint.

Parietal. The parietal forms the anteromedial part of the temporal fossa (Figures 2, 4), which is flat and vertical. The parietal/squamosal suture is opened.

Alisphenoid. The alisphenoid is exposed ventral to the parietal, anterior to the squamosal and dorsal to the pterygoid (Figure 2.2), and is anteroposteriorly long $(45.0 \mathrm{~mm}+$ long and $32.0 \mathrm{~mm}$ high) even though its anterior part is broken away. A ventral exposure of the alisphenoid can be seen in the pterygoid sinus fossa as Tanaka and Taruno (2017) described it on a specimen of Balaenoptera edeni. The alisphenoid places posterior to the squamosal and lateral to the pterygoid. 


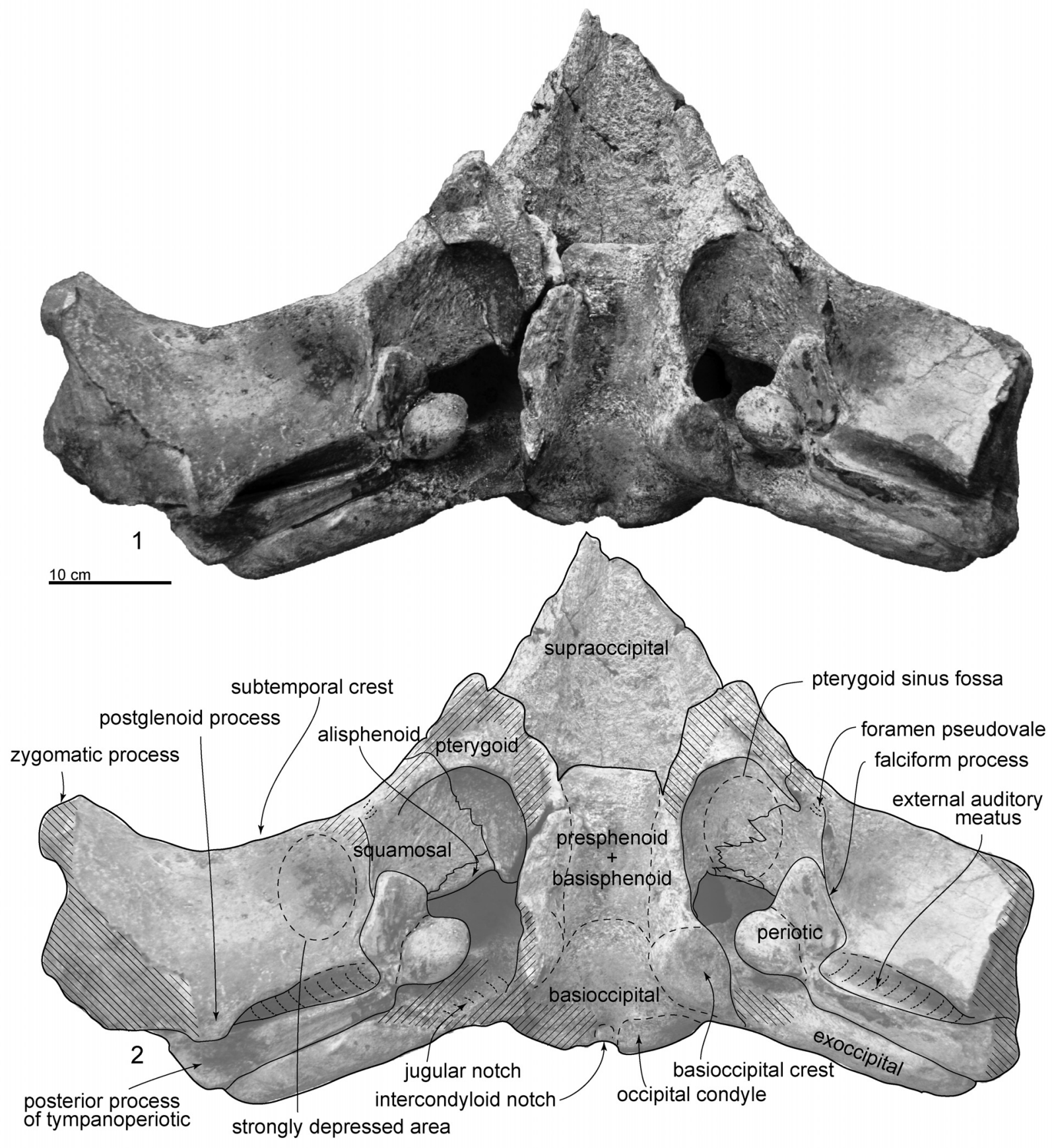

FIGURE 3. 1-2, Skull of cf. Miobalaenoptera numataensis (YPM 11851) in ventral view., photo (1), line drawing (2).

Pterygoid. The pterygoid is located anteromedial to the squamosal, and forms the anteromedial part of the pterygoid sinus fossa (Figure 3). Posteriorly, the pterygoid forms for the foramen pseudovale (Marx et al., 2016, Figure 3.4) with the squamosal. The ventral surface of the pterygoid is damaged.

Squamosal. The squamosal has a broken base of the zygomatic process is thick (Figures 2-4). The lateral surface of the zygomatic process has two anteroposteriorly long triangular shallow fossae, which are for the sternocephalicus. Medial to the zygomatic process, the squamosal has a transversely long sigmoidal squamosal cleft (about $170.0 \mathrm{~mm}$ wide), running from the alisphenoid, squamosal and pterygoid junction (Figure 4.4). 


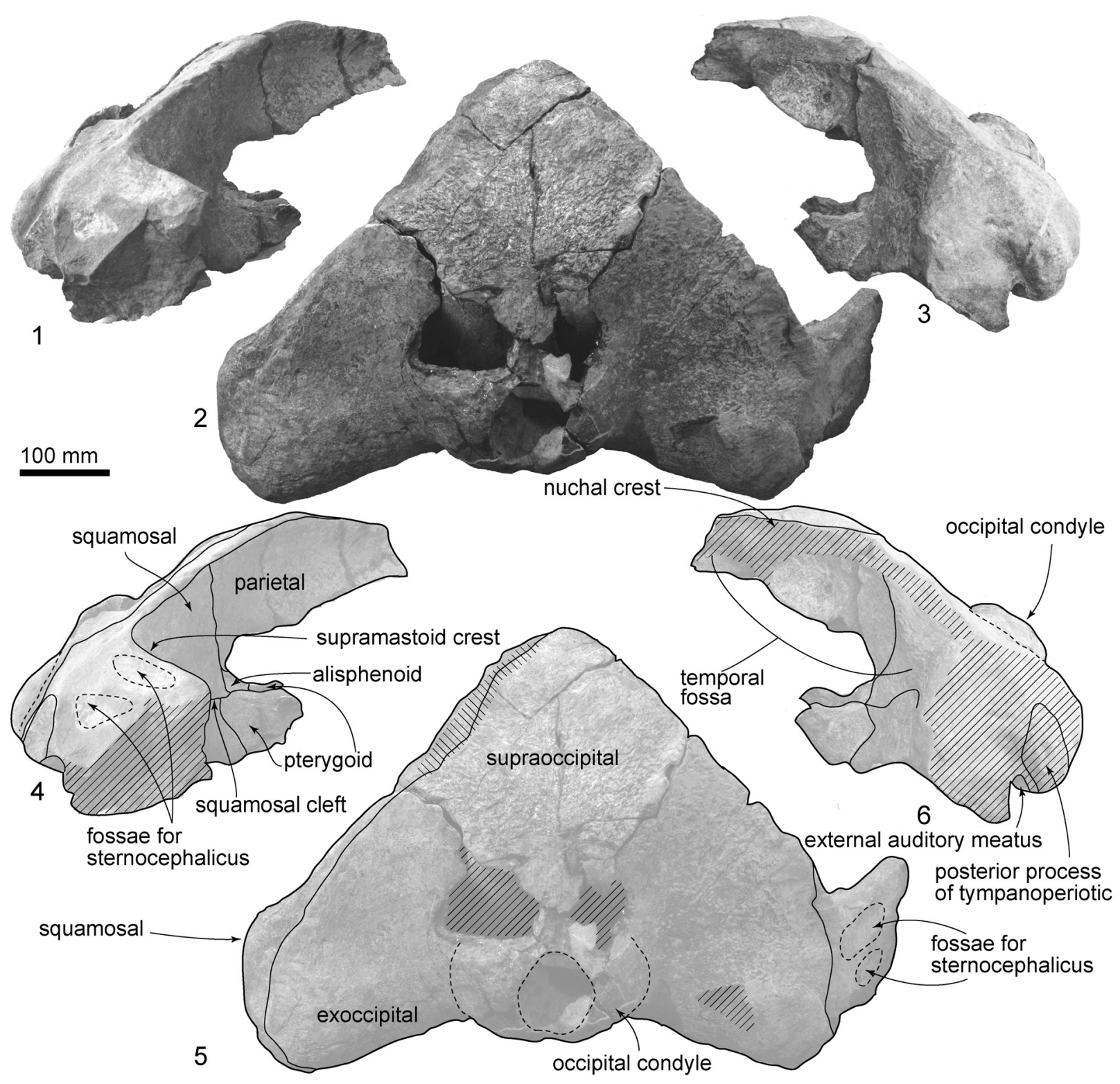

FIGURE 4. 1-6, Skull of cf. Miobalaenoptera numataensis (YPM 11851) in right lateral view (1 and 4), dorsal view (2, $5)$, left lateral view $(3,6)$, photos (1-3), line drawings (4-6).

In ventral view (Figure 3 ), the squamosal has a sharp falciform process, which runs anteroposteriorly just lateral to the periotic. The anterior end of the falciform process forms the lateral border of the foramen pseudovale (about $260.0 \mathrm{~mm}$ wide). Medial to the foramen pseudovale, the pterygoid sinus fossa shows the squamosal/pterygoid suture is almost closed but is visible. An area, lateral to the falciform process and posterior to the subtemporal crest, is strongly depressed. The posterior end of the squamosal forms a dorsoventrally deep external auditory meatus (about $25.0 \mathrm{~mm}$ long, $220.0+\mathrm{mm}$ wide, and $600.0+\mathrm{mm}$ maximum depth) (Figure 4.6). The squamosal connects to the anterior, posterior and dorsal surfaces of the posterior process of the tympanoperiotic (Figure 4.4, 4.6).

Exoccipital. The exoccipital is fused to the supraoccipital and basioccipital completely, and the joints are obliterated. The lateral end of the exoccipital is rounded (Figure 2.3, 2.4). The posterolateral end of the exoccipital projects posterolaterally in dorsal view (Figure 4.2, 4.5). In ventral view (Figure 3 ), the anterior and posterior borders of the 

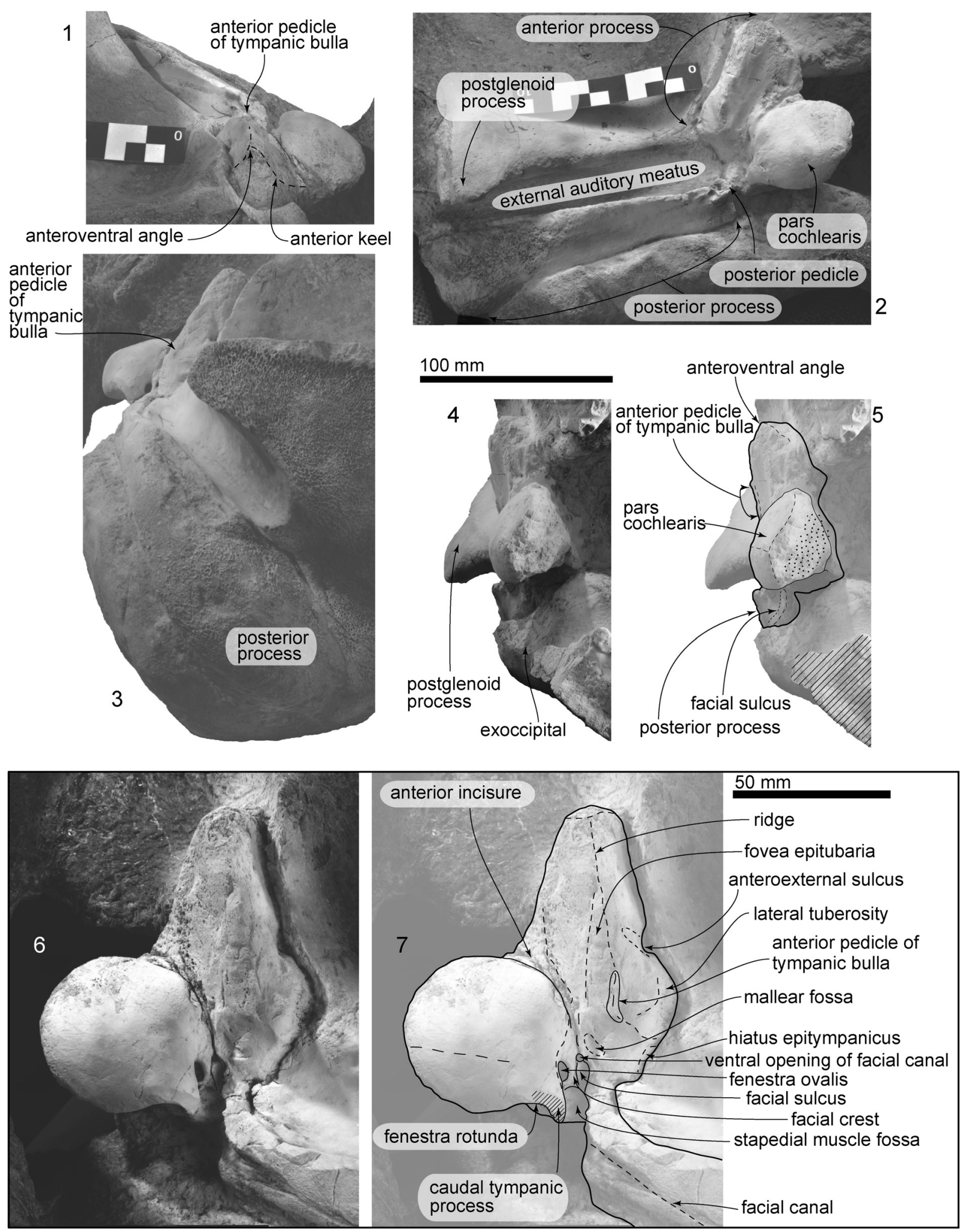

FIGURE 5. 1-7, Periotics of cf. Miobalaenoptera numataensis (YPM 11851) in right side $(1,2,4,5)$, left side (3, 6, 7), anterior view (1), ventral view $(2,6,7)$, lateral view $(3)$, medial view $(4,5)$, photos $(1-4,6)$, line drawing $(5,7)$. 
TABLE 1. Measurements in mm of the skull, cf. Miobalaenoptera numataensis (YPM 11851). Measurements are rounded to the nearest $0.5 \mathrm{~mm}$.

\begin{tabular}{lc}
\hline & $\mathbf{m m}$ \\
\hline Total length as preserved & 516.0 \\
Breadth across exoccipitals & 620.0 \\
Maximum width as preserved & 807.0 \\
Length of supraoccipital & 516.0 \\
Foramen magnum width & 79.0 \\
Foramen magnum height & 91.0 \\
Maximum width of occpital condyles & 174.0 \\
\hline
\end{tabular}

exoccipital are parallel at the medial portion and anteroposteriorly shorter at the lateral end.

Supraoccipital. The supraoccipital is a wide triangle (Figure 4), and its lateral border is a very weakly curved nuchal crest. The dorsal surface of the supraoccipital is depressed medially.

Presphenoid and basisphenoid. The presphenoid and basisphenoid are fused, and lie anterior to the basioccipital and medial to the pterygoid (Figure 3). The anterior border of the presphenoid shows an open joint with the vomer. The basisphenoid is an anteriorly wider trapezoidal. The lateral borders are the pharyngeal crests.

Basioccipital. The basioccipital is located posterior to the basisphenoid with a fused but visible joint, and is posteriorly wide in ventral view (Figure 3 ). The basioccipital crest is transversely wide (42.0 $\mathrm{mm}$ thick, $95.0 \mathrm{~mm}$ long, and $65.0 \mathrm{~mm}$ wide). The basioccipital crests widen posteriorly.

Exoccipital. The occipital condyle does not protrude posteriorly much and does not have a clear lateral border. The foramen magnum is dorsoventrally higher oval. Lateral to the occipital condyle, a wide jugular notch (about $20.0 \mathrm{~mm}$ wide) runs anteromedial to posterolateral.

Periotic. Both periotics are in situ (Figure 5, Table 2 ). The periotic has a short, narrow, and dorsoventrally high anterior process, which is triangular in ventral view, and blunt square in medial view. A dorsoventrally shallow pars cochlearis $(16.5 \mathrm{~mm}$ deep) is longer than the anterior process. A robust posterior process has an anteroposteriorly long lateral end.

The anterior process projects anteriorly and has an anteroposteriorly long ridge on the ventral surface, which is the lateral margin of the fovea epitubaria. Posterior to the ridge, there is an anteroposteriorly long anterior pedicle of the tympanic bulla (16.5 $\mathrm{mm}$ long). The lateral tuberosity projects laterally and is located lateral to the anterior pedicle of the tympanic bulla. Anterior to the lateral tuberosity and medial to the falciform process, there is an excavation, which is a deeply excavated anteroexternal sulcus (about $40.0 \mathrm{~mm}$ posterior from the anterior end of the anterior process). A deep and anteriorly opened crescent shaped mallear fossa ( $6.5 \mathrm{~mm}$ wide) is present posteromedial to the anterior pedicle.

An anteroposteriorly long pars cochlearis (52.0 $\mathrm{mm}$ long except the caudal tympanic process, $53.5+\mathrm{mm}$ wide) has a flat ventral surface with a transversely long blunt ridge at the level of the fenestra ovalis and posterior end of the lateral tuberosity. The medial margin of the pars cochlearis is sigmoidal in ventral view. A broken base of the caudal tympanic process is located posterior to the fenestra ovalis, and the preserved part is robust. Dorsomedial to the caudal tympanic process, a small fenestra rotunda opens posteriorly (7.1 $\mathrm{mm}$ in diameter). The medial surface of the pars cochlearis is covered by the matrix.

A small ventral opening of the facial canal (2.5 $\mathrm{mm}$ in diameter) opens and continues to a shallow facial sulcus (9.0 mm long). An anteroposteriorly long elliptical fenestra ovalis $(5.5 \mathrm{~mm}$ in length and $1.5 \mathrm{~mm}$ in width) is located posteromedial to the ventral opening of the facial canal. The facial crest is mediolaterally thick and is separated from the facial canal and fenestra ovalis.

The posterior process of the tympanoperiotic is mediolaterally wide and anteroposteriorly long (Table 2). The posterior process at the lateral end

TABLE 2. Measurements in $\mathrm{mm}$ of the periotic, cf. Miobalaenoptera numataensis (YPM 11851). Measurements are rounded to the nearest $0.5 \mathrm{~mm}$.

\begin{tabular}{lc}
\hline & $\mathbf{m m}$ \\
\hline length of anterior process, from anteroventral angle to anterior incisure & 46.0 \\
length of pars cochlearis, from anterior incisure to posterior margin around the aperture for the & 50.0 \\
cochlear aqueduct of pars cochlearis & 190.5 \\
posterior process mediolateral width & 52.0 \\
maximum anteroposterior length of posterior process & \\
\hline
\end{tabular}


is dorsoventrally higher elliptical and forms the lateral surface of the skull. The posterior process is surrounded by the squamosal except on the ventral side. There is a long and shallow facial canal, running transversely on the ventral surface of the posterior process. At the anterior end of the posterior process, anterior to the facial sulcus, there is a mediolaterally wide posterior pedicle of the tympanic bulla. A small fenestra rotunda opens posteriorly.

\section{PHYLOGENETIC ANALYSIS}

The phylogenetic position of YPM 11851 is analyzed using the datamatrix of Tanaka and Watanabe (2019a), which was derived from the one of Marx et al. (2017). This study adds a new character and specimen (YPM 11851) to the previous datamatrix, containing 273 morphological characters and 99 taxa (see Appendices 1 to 3) with minor modifications (see Appendix 4). Percentages of coded data of YPM 11851 are $17.5 \%$ (including soft tissue characters) and $18.0 \%$ (excluding soft tissue).

The matrix was managed with Mesquite 2.75 (Maddison and Maddison, 2011), then analysis was performed using TNT version 1.5 (Goloboff and Catalano, 2016). All of the characters were treated as unordered and unweighted, with backbone constraint of extant taxa, based on a topology of the molecular tree by McGowen et al. (2009). The analysis used New Technology Search, with recover minimum length trees $=1000$ times.

\section{RESULTS}

The phylogenetic analysis shows 1994 shortest trees of 1329 steps each. The $50 \%$ majority rule consensus tree (Figure 6 and Appendix 5) places YPM 11851 in a clade with the holotype of Miobalaenoptera numataensis (NFL 18) among the Balaenopteridae. The topology among the Balaenopteridae is more or less the same as that of Tanaka and Watanabe (2019a), except for forming a clade of Incakujira anillodefuego and ( $M$. numataensis + YPM 11851). A higher level branching pattern of this study is gained as (((Balaenopteridae + a clade of Uranocetus gramensis and Pelocetus calvertensis) Cetotheriidae) a clade of Isanacetus, Parietobalaena and related taxa). The pattern is different from that of Tanaka and Watanabe (2019a) in terms of branching order of the Cetotheriidae and the clade of Isanacetus, Parietobalaena and related taxa.

\section{DISCUSSION}

\section{Lateral Ridge of the Fovea Epitubaria}

The holotype of Miobalaenoptera numataensis (NFL 18) and cf. M. numataensis (YPM 11851) have similarities such a dorsoventrally thin pars cochlearis, a straight and horizontally expanded subtemporal crest of the squamosal, strongly posterolaterally diverged basioccipital crest, and a sharp anteroposteriorly long straight ridge (the lateral ridge of the fovea epitubaria) at the ventral surface of the anterior process of the periotic (Character 273 in this study). The ridge is a lateral margin of the fovea epitubaria. Therefore, a more basal species, such as Whakakai waipata (Tsai and Fordyce, 2016, figure 3) shows the same relationships of structures with NFL 18 and YPM 11851 (there is an anteriorly narrow triangular fovea epitubaria, medial to the ridge and anterior to the mallear fossa), and this result allows the consideration of the homology of the ridge of NFL 18, YPM 11851, and other species.

The condition of the lateral ridge of the fovea epitubaria on Miobalaenoptera numataensis (NFL 18) and YPM 11851 is straight and sharp, running to the anterior pedicle and is located more anterior to the modern Balaenoptera spp. This newly added character shows mosaic states distribution among the Mysticeti. For example, among the Cetotheriidae, the state of having a straight sharp ridge on the center of the anterior process can be seen on that of Tiucetus rosae (Marx et al., 2017). Other members of the Cetotheriidae, such as Herpetocetus morrowi (see El Adli et al., 2014) and Herpetocetus sp. (USNM 299652 of Geisler and Luo, 1996, and NFL 2083 of Tanaka and Watanabe, 2019b) also show a sharp ridge, but one that is located lateral to the central axis of the anterior process. Other members of the Cetotheriidae, such as Brandtcetus chongulek (Gol'din and Startsev, 2014) and Piscobalaena nana (Bouetel and de Muizon, 2006) show a sharp ridge, but a curved one. On the other hand, among the Cetotheriidae, some members show the ridge as weak and curved, such as Mithridatocetus eichwaldi (Gol'din and Startsev, 2017).

The extant balaenopterids show blunt lateral ridges of the fovea epitubaria, not sharp one of $M$. numataensis. The modern balaenopterid ridges exist only in the posterior portion of the anterior process of the periotic. On the other hand, the lateral ridge of $M$. numataensis runs almost the entire part of the anterior process in ventral view. 


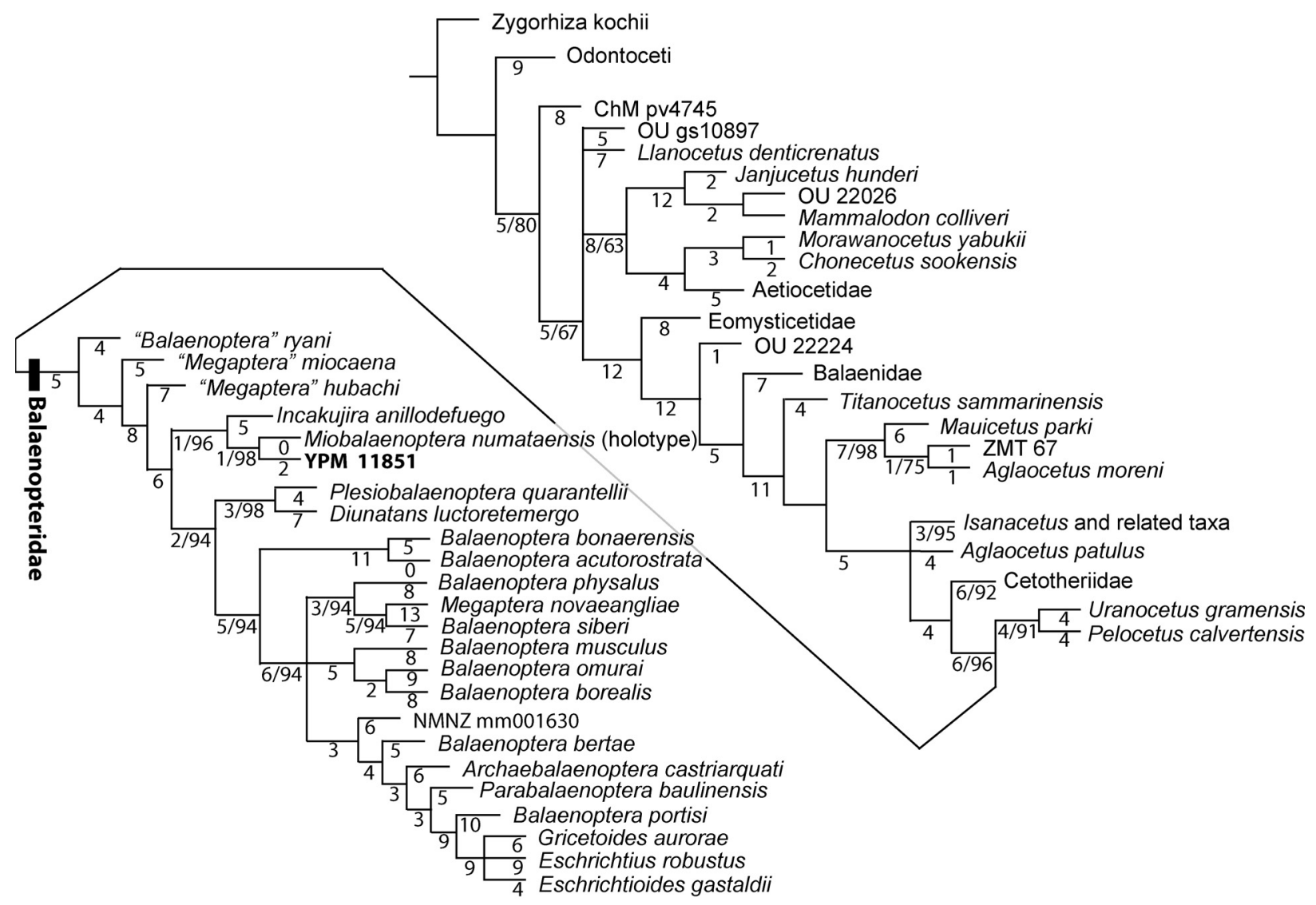

FIGURE 6. 50\% majority rule consensus tree of 1994 most parsimonious trees to show the phylogenetic position of YPM 11851.The clades Odontoceti, Aetiocetidae, Eomysticetidae, Balaenidae, Cetotheriidae and a clade comprising Isanacetus, Parietobalaena and related taxa are collapsed (see Appendix 5 for cladogram with all taxa shown). The numbers on the each branch are branch lengths. The numbers next to the branch lengths show the percentages of the shortest trees supporting each node. $100 \%$ supported nodes are omitted the percentages.

Among the fossil balaenopterids, "Megaptera" miocaena of Kellogg (1922), Parabalaenoptera baulinensis of Zeigler et al. (1997), Fragilicetus velponi of Bisconti and Bosselaers (2016), and Diunatans luctoretemergo of Bosselaers and Post (2010), show weak or blunt lateral ridges of the fovea epitubaria. Plesiobalaenoptera quarantellii of Bisconti (2010), shows a ridge with the same condition as the Miobalaenoptera numataensis (sharp and continues to the anterior pedicle), but can be distinguished from M. numataensis by having a larger lateral tuberosity and wider anterior process. Incakujira anillodefuego of Marx and Kohno (2016), shows no ridge anterior to the broken base of the anterior pedicle (Marx and Kohno, 2016, figure 10). "Balaenoptera" ryani of Hanna and McLellan (1924) also shows no ridge.

The functional meaning of having the sharp, straight and long lateral ridges of the fovea epitubaria is unknown. The lateral ridge of the fovea epitubaria is related to the position, size, and/or shape of the accessory ossicle, which suggests that the variations of the ridge are possibly relate to hearing.

\section{Comparison between Incakujira anillodefuego and YPM 11851 + Miobalaenoptera numataensis}

The result of phylogenetic analysis supports that (Incakujira anillodefuego [YPM $11851+$ the holotype of Miobalaenoptera numataensis]) as a clade. However, there are several differences between them. I. anillodefuego differs from $M$. numataensis and YPM 11851 by having lower basioccipital crests, anteriorly bulged subtemporal crest in ventral view, and more posteriorly located foramen pseudovale ( $M$. numataensis and YPM 11851 have the foramen pseudovale at the anterior margin of the subtemporal crest). I. anillodefuego differs from YPM 11851 by having a posteriorly suddenly widen nuchal crest, and well posteriorly projected occipital condyle. I. anillodefuego differs 
TABLE 3. Morphological differences between Miobalaenoptera numataensis (NFL 18) and cf. M. numataensis (YPM 11851).

\begin{tabular}{lll}
\hline & \multicolumn{1}{c}{$\begin{array}{c}\text { YPM 11851 } \\
\text { Referred }\end{array}$} & $\begin{array}{c}\text { NFL 18 } \\
\text { Holotype }\end{array}$ \\
\hline basioccipital crest & dorsoventrally deeper & shallower \\
area between basioccipital crests & narrower & wider \\
ventral surface of anteromedial portion of squamosal & excavated & flat \\
anterior process & dorsoventrally deeper & shallower \\
shape of the anterior process & wider & narrower \\
lateral tuberosity location & more posterior & anterior \\
anteroexternal sulcus & more posterior & anterior \\
pars cochlearis & dorsoventrally thicker & thinner \\
medial margin of pars cochlearis in ventral view & sigmoidal & straight \\
\hline
\end{tabular}

from the holotype of $M$. numataensis in several features such as having a weakly excavated orbit in dorsoventral view, a more slender zygomatic process, smaller postorbital process in lateral view, anteroventrally bent anterior tip of the zygomatic process, longer and robust caudal process of the periotic (YPM 11851 does not preserve the process), and shallow area lateral from the fenestra rotunda and dorsal from the posteroventral margin of the pars cochlearis ( $M$. numataensis and YPM 11851 show deeper areas). Thus, I. anillodefuego is taxonomically different from $M$. numataensis and YPM 11851.

\section{Differences between YPM 11851 and the holotype of Miobalaenoptera numataensis}

YPM 11851 is identified as cf. M. numataensis preliminary, and cannot be identified as the species, because of limited knowledge on ontogenetic and other variations of the species. Between YPM 11851 and NFL 18, there are some morphological differences as noticed below (see also Table 3). YPM 11851 has a dorsoventrally deeper (or higher) basioccipital crest, a narrower area between the basioccipital crests, a deeper area on the anteromedial portion of the ventral surface of the squamosal (NFL 18 shows that as a flat area), a dorsoventrally deeper anterior process of the periotic (NFL 18 shows that as very shallow), a more posteriorly located lateral tuberosity (Character 157) (NFL 18 shows that much more anterior), a deeply excavated anteroexternal sulcus locating about $40.0 \mathrm{~mm}$ posterior from the anterior end of the anterior process (NFL 18 shows the sulcus more anteriorly, about $24.0 \mathrm{~mm}$ posterior from the anterior end of the anterior process) (Figure 7), a dorsoventrally thicker pars cochlearis (a thinner pars cochlearis was stated as a diagnosis for NFL
18), and a sigmoidal lateral margin of the pars cochlearis in ventral view (NFL 18 shows a straight medial margin) (Figure 7). In addition, two analyzed characters of the anterior process of the periotic are coded differently between NFL 18 and YPM 11851 (Characters 148 and 151: anterior process shape and length) (see Table 3 ), because YPM 11851 shows a larger anterior process than that of NFL 18.

The width of the squamosal and occipital bones are grown on Balaenoptera acutrostrata (Nakamura and Kato, 2014). Thus some of these differences between YPM 11851 and NFL 18 might cause of ontogenetic variation. The anterior process is known as a part largely changed through growth on an extant balaenopterid study (Bisconti, 2001). Based on these conditions, YPM 11851 possibly shows an older state than NFL 18 as above. However, possible ontogenetic stages of these specimens are confusing. Cranial joints (parietal/squamosal, and basisphenoid/basioccipital joints) suggest that YPM 11851 is younger than NFL 18. Especially the parietal/squamosal of YPM 11851 is opened, but that of NFL 18 is closed and invisible.

Other differences between YPM 11851 and NFL 18 on the basioccipital and also squamosal (Table 3 ) can be seen on modern Balaenoptera acutorostrata (an adult of 25 years old, $8.4 \mathrm{~m}$ total long at Toyohashi Museum of Natural History, and a juvenile at Hokkaido University Botanic Garden). This is a limited examination, but it suggests that morphological variations between YPM 11851 and NFL 18 on the basioccipital and also squamosal are possibly ontogenetic variations.

The number of $M$. numataensis specimens is simply not enough to consider ontogenetic variations. YPM 11851 has similarities with NFL 18, but 


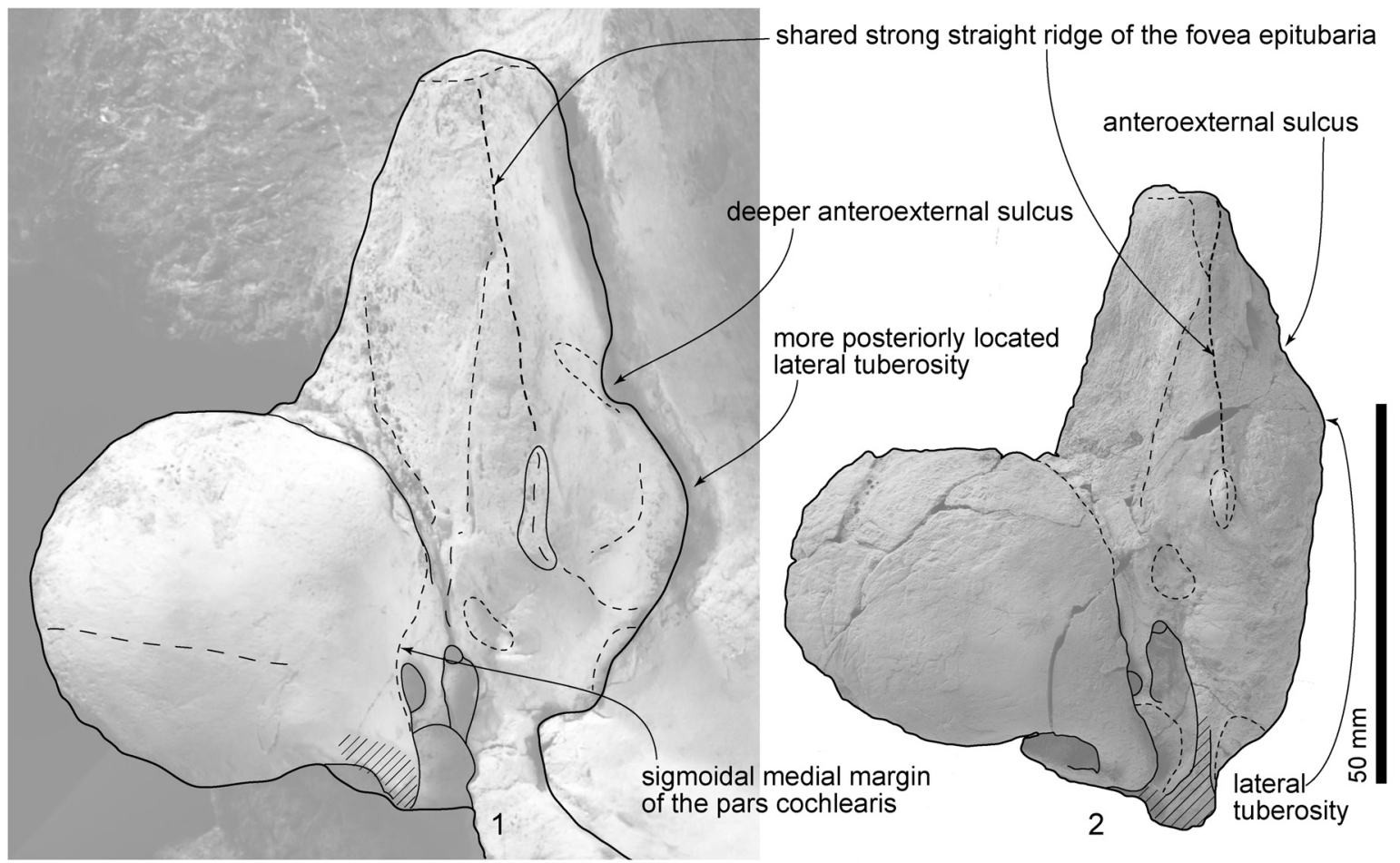

FIGURE 7. Comparison between the holotype and referred specimens of cf. Miobalaenoptera numataensis periotics in ventral view. YPM 11851 (1), holotype NFL 18 (2). Illustration of M. numataensis is modified from Tanaka and Watanabe (2019a).

cannot identify as the same species in this study, but add morphological information including supposed ontogenetic variation. A third similar specimen will be very informative to picture it.

\section{CONCLUSION}

Here we describe an early balaenopterid, cf. Miobalaenoptera numataensis (YPM 11851) from a late Miocene to early Pliocene sediment in Yamagata Prefecture, Japan. The new specimen is comparable to $M$. numataensis by having a straight and sharp lateral ridge of the fovea epitubaria at the ventral surface of the periotic, and a dorsoventrally thin pars cochlearis. YPM 11851 shows differences from the holotype of $M$. numataensis such as having a dorsoventrally deeper basioccipital crest, a narrower area between the basioccipital crests, a deeper area on the anteromedial portion of the ventral surface of the squamosal, a dorsoventrally deeper anterior process of the periotic, a more posteriorly located lateral tuberosity, a deeply excavated anteroexternal sulcus locating about $40.0 \mathrm{~mm}$ posterior from the anterior end of the anterior process, a dorsoventrally thicker pars cochlearis, and a sigmoidal medial margin of the pars cochlearis in ventral view. Morphological variations among fossil species have been merely reported. Some of these variations on the periotic are possibly ontogenetic variations. The new specimen expands morphological variations, but the third comparable specimen might solve the question on variations.

\section{ACKNOWLEDGEMENTS}

We thank S. Ito (Shinjo City, Yamagata Prefecture) for collecting the specimen, students of Yamagata University for preparation. We also thank D. Savage (Touohgakkan Senior High School) for revising our manuscript. Thanks go to T. Kimura (Gunma Museum of Natural History), CH Tsai (National Taiwan University) and an anonymous reviewer for giving constructive comments. Y. Tanaka thanks M. Kato (Botanic Garden, Hokkaido University) and K. Yasui (Toyohashi Museum of Natural History) for giving access to the comparative materials. 


\section{REFERENCES}

Bisconti, M. 2001. Morphology and postnatal growth trajectory of rorqual petrosal. Italian Journal of Zoology, 68:87-93. https://doi.org/10.1080/11250000109356390

Bisconti, M. 2007a. A new basal balaenopterid whale from the Pliocene of northern Italy. Palaeontology, 50:1103-1122. https://doi.org/10.1111/j.1475-4983.2007.00696.x

Bisconti, M. 2007b. Taxonomic revision and phylogenetic relationships of the rorqual-like mysticete from the Pliocene of Mount Pulgnasco, northern Italy (Mammalia, Cetacea, Mysticeti). Palaeontographia Italica, 91:85-108.

Bisconti, M. 2010. A new balaenopterid whale from the Late Miocene of the Stirone River, northern Italy (Mammalia, Cetacea, Mysticeti). Journal of Vertebrate Paleontology, 30:943958. https://doi.org/10.1080/02724631003762922

Bisconti, M. and Bosselaers, M. 2016. Fragilicetus velponi: a new mysticete genus and species and its implications for the origin of Balaenopteridae (Mammalia, Cetacea, Mysticeti). Zoological Journal of the Linnean Society, 177:450-474. https://doi.org/10.1111/zoj.12370

Boessenecker, R.W. 2013. A new marine vertebrate assemblage from the Late Neogene Purisima Formation in Central California, part II: pinnipeds and cetaceans. Geodiversitas, 35:815-940. https://doi.org/10.5252/g2013n4a5

Boessenecker, R.W. and Fordyce, R.E. 2015. Anatomy, feeding ecology, and ontogeny of a transitional baleen whale: a new genus and species of Eomysticetidae (Mammalia: Cetacea) from the Oligocene of New Zealand. PeerJ, 3:e1129. https://doi.org/10.7717/peerj.1129

Bosselaers, M. and Post, K. 2010. A new fossil rorqual (Mammalia, Cetacea, Balaenopteridae) from the Early Pliocene of the North Sea, with a review of the rorqual species described by Owen and Van Beneden. Geodiversitas, 32:331-363. https://doi.org/10.5252/g2010n2a6

Bouetel, V. and de Muizon, C. 2006. The anatomy and relationships of Piscobalaena nana (Cetacea, Mysticeti), a Cetotheriidae s. s. from the early Pliocene of Peru. Geodiversitas, 28:319-395.

de Buffrénil, V., Dabin, W., and Zylberberg, L. 2004. Histology and growth of the cetacean petrotympanic bone complex. Journal of Zoology, 262:371-381. https://doi.org/10.1017/ s0952836903004758

Chen, I., Chou, L.-S., Chen, Y.-J., and Watson, A. 2011. The maturation of skulls in postnatal Risso's dolphins (Grampus griseus) from Taiwanese waters. Taiwania, 56:177-185.

Cope, E.D. 1872. On an extinct whale from California. Proceedings of the Academy of Natural Sciences of Philadelphia, 24:29-30.

Cozzi, B., Podestà, M., Mazzariol, S., and Zotti, A. 2012. Fetal and early post-natal mineralization of the tympanic bulla in fin whales may reveal a hitherto undiscovered evolutionary trait. PLoS ONE, 7:e37110. https://doi.org/10.1371/journal.pone.0037110

Cozzi, B., Podestà, M., Vaccaro, C., Poggi, R., Mazzariol, S., Huggenberger, S., and Zotti, A. 2015. Precocious ossification of the tympanoperiotic bone in fetal and newborn dolphins: an evolutionary adaptation to the aquatic environment? The Anatomical Record, 298:12941300. https://doi.org/10.1002/ar.23120

Dathe, F. 1983. Megaptera hubachi n. sp., ein fossiler Bartenwal aus marinen Sandsteinschichten des tietferen Pliozäns Chiles. Zeitschrift fur geologische wissenschaften, 11:813-848.

Deméré, T.A. 1986. The fossil whale, Balaenoptera davidsonii (Cope 1872), with a review of other Neogene species of Balaenoptera (Cetacea: Mysticeti). Marine Mammal Science, 2:277-298. https://doi.org/10.1111/j.1748-7692.1986.tb00136.x

El Adli, J.J., Deméré, T.A., and Boessenecker, R.W. 2014. Herpetocetus morrowi (Cetacea: Mysticeti), a new species of diminutive baleen whale from the Upper Pliocene (Piacenzian) of California, USA, with observations on the evolution and relationships of the Cetotheriidae. Zoological Journal of the Linnean Society, 170:400-466. https://doi.org/10.1111/zoj.12108

Fordyce, R.E. and de Muizon, C. 2001. Evolutionary history of whales: a review, p. 169-234. In Mazin, J.-M. and de Buffrenil, V. (eds.), Secondary Adaptation of Tetrapods to Life in Water. Pfeil, München, Germany.

Galatius, A., Berta, A., Frandsen, M.S., and Goodall, R.N.P. 2011. Interspecific variation of ontogeny and skull shape among porpoises (Phocoenidae). Journal of Morphology, 272:136-148. https://doi.org/10.1002/jmor.10900 
Galatius, A. and Kinze, C.C. 2003. Ankylosis patterns in the postcranial skeleton and hyoid bones of the harbour porpoise (Phocoena phocoena) in the Baltic and North Sea. Canadian Journal of Zoology, 81:1851-1861. https://doi.org/10.1139/z03-181

Geisler, J.H. and Luo, Z. 1996. The petrosal and inner ear of Herpetocetus sp. (Mammalia: Cetacea) and their implications for the phylogeny and hearing of archaic mysticetes. Journal of Paleontology, 70:1045-1066. https://doi.org/10.1017/S0022336000038749

Gol'din, P. and Startsev, D. 2014. Brandtocetus, a new genus of baleen whales (Cetacea, Cetotheriidae) from the late Miocene of Crimea, Ukraine. Journal of Vertebrate Paleontology, 34:419-433. https://doi.org/10.1080/02724634.2013.799482

Gol'din, P. and Startsev, D. 2017. A systematic review of cetothere baleen whales (Cetacea, Cetotheriidae) from the Late Miocene of Crimea and Caucasus, with a new genus. Papers in Palaeontology, 3:49-68. https://doi.org/10.1002/spp2.1066

Goloboff, P.A. and Catalano, S.A. 2016. TNT version 1.5, including a full implementation of phylogenetic morphometrics. Cladistics, 32:221-238. https://doi.org/10.1111/cla.12160

Gray, J.E. 1864. On the Cetacea which have been observed in the seas surrounding the British Island. Proceedings of the Zoological Society of London, 2:195-248.

Gutstein, C.S., Cozzuol, M.A., Vargas, A.O., Suárez, M.E., Schultz, C.L., and Rubilar-Rogers, D. 2009. Patterns of skull variation of Brachydelphis (Cetacea, Odontoceti) from the Neogene of the Southeastern Pacific. Journal of Mammalogy, 90:504-519. https://doi.org/10.1644/07MAMM-A-081.1

Hampe, O., Franke, H., Hipsley, C.A., Kardjilov, N. and Müller, J. 2015. Prenatal cranial ossification of the humpback whale (Megaptera novaeangliae). Journal of Morphology, 276:564-582. https://doi.org/10.1002/jmor.20367

Hanna, G.D. and McLellan, M.E. 1924. A new species of fin whale from the type locality of the Monterey Group. Proceedings of the California Academy of Sciences, 13:237-241.

Hasegawa, Y., Koda, Y., Yanagisawa, Y., Sato, Y., and Omori, S. 1988. On a fossil cetacean off the coast of Oarai-machi, Ibaraki Prefecture, p. 48-50. In Hasegawa, Y. (ed.), Studies on the Fossil Marine Mammals from Japan. The Grant-in-Aid for Scientific Research from the Ministry of Education, Science and Culture in the 62nd fiscal year of Showa.

Hasegawa, Y., Koizumi, A., Matushima, Y., Imanaga, I., and Hirata, D. 1991. Fossil remains from the Nakatsu Group, p. 1-98. In Hasegawa, Y. (ed.), Fossil Remains from the Nakatsu Group, Kanagawa Prefectural Museum, Yokohama.

Hasegawa, Y., Takakuwa, Y., and Nakajima, H. 2002. A balaenopterid whale from the Haraichi Formation (Middle Miocene), Tomioka Group, Annaka City, Gunma Prefecture, Japan. Bulletin of Gunma Museum of Natural History, 6:39-44.

Hatai, K., Hayasaka, S., and Masuda, K. 1963. Some fossil tympanics from the Mizuho period of northern Japan. Saito Ho-on Kai Museum of Natural History, Research Bulletin, 32:5-17.

Ichishima, H. 2005. A re-evaluation of some Japanese cetacean fossils. Memoir of the Fukui Prefectural Dinosaur Museum, 4:1-20.

Ito, H. and Miyazaki, N. 1990. Skeletal development of the striped dolphin (Stenella coeruleoalba) in Japanese waters. Journal of the Mammalogical Society of Japan, 14:79-96. https://doi.org/10.11238/jmammsocjapan1987.14.79

Iwaki Educational and Cultural Corporation. 1989. Excavation Report of Fossil Whales from Yotsukura-cho, Iwaki City. Board of Education, Iwaki City, Fukushima Prefecture, Japan.

Kasuya, T. 1973. Systematic consideration of recent toothed whales based on the morphology of tympano-periotic bone. Scientific Reports of the Whales Research Institute Tokyo, 25:1-103.

Kellogg, R. 1922. Description of the skull of Megaptera miocaena, a fossil humpback whale from the Miocene diatomaceous earth of Lompoc, California. Proceedings of the United States National Museum, 61:1-18. https://doi.org/10.5479/si.00963801.61-2435.1

Kimura, M. and Kanaya, K. 1996. On the fossil cetacea from the Haboro-cyo, Hokkaido, Japan. Kyoudo to Kagaku, 109:23-32.

Kimura, T., Adaniya, A., Oishi, M., Marx, F., Hasegawa, Y., and Kohno, N. 2015. A Late Miocene balaenopterid ("Shimajiri-kujira") from the Okamishima Formation, Shimajiri Group, Miyako Island, Okinawa, Japan. Bulletin of Gunma Museum of Natural History, 19:39-48.

Kohno, N., Koike, H., and Narita, K. 2007. Outline of fossil marine mammals from the Middle Miocene Bessho and Aoki Formations, Nagano Prefecture, Japan. Research Report of the Shinshushinmachi Fossil Museum, 10:1-45.

Kurihara, N. and Oda, S. 2009. Effects of size on the skull shape of the bottlenose dolphin (Tursiops truncatus). Mammal Study, 34:19-32. https://doi.org/10.3106/041.034.0104 
Maddison, W.P. and Maddison, D.R. 2011. Mesquite: a modular system for evolutionary analysis. Available at http://mesquiteproject.org.

Marx, F.G. and Kohno, N. 2016. A new Miocene baleen whale from the Peruvian desert. Royal Society Open Science, 3:1-27. https://doi.org/10.1098/rsos.160542

Marx, F. G., Lambert, O., and Uhen, M. D. 2016. Cetacean Paleobiology. John Wiley and Sons, New York.

Marx, F.G., Lambert, O., and de Muizon, C. 2017. A new Miocene baleen whale from Peru deciphers the dawn of cetotheriids. Royal Society Open Science, 4:1-22. https://doi.org/ $10.1098 /$ rsos. 170560

McGowen, M.R., Spaulding, M., and Gatesy, J. 2009. Divergence date estimation and a comprehensive molecular tree of extant cetaceans. Molecular Phylogenetics and Evolution, 53:891-906. https://doi.org/10.1016/j.ympev.2009.08.018

Mead, J.G. and Fordyce, R.E. 2009. The therian skull: a lexicon with emphasis on the odontocetes. Smithsonian Contributions to Zoology, 627:1-248. https://doi.org/10.5479/ si.00810282.627

Moran, M.M., Bajpai, S., George, J.C., Suydam, R., Usip, S., and Thewissen, J.G.M. 2015. Intervertebral and epiphyseal fusion in the postnatal ontogeny of cetaceans and terrestrial mammals. Journal of Mammalian Evolution, 22:93-109. https://doi.org/10.1007/s10914-0149256-7

Moriya, S., Danhara, T., Iwano, H., Yamashita, T., Nakajima, T., and Chinzei, K. 2008. Fissiontrack ages of the Pliocene strata in the Shinjo Basin, Yamagata Prefecture. The Journal of the Geological Society of Japan, 114:1-15. https://doi.org/10.5575/geosoc.114.1

Nagasawa, K. 1993. A fossil caudal vertebra of baleen whale from the Pliocene Noguchi Formation, Okura-mura, Yamagata Prefecture, Northeast Japan. Bulletin of the Yamagata Prefectural Museum, 14:15-22.

Nagasawa, K. 1995. Reconsideration of fossil mandibles of baleen whale from the Upper Miocene, Oe-machi, Yamagata Prefecture, Northeast Japan. Bulletin of the Yamagata Prefectural Museum, 16:31-38.

Nagasawa, K. 1999. Fossil cetacea from the Pliocene, Noguchi Formation of Mamurogawa Town, Yamagata Prefecture, p. 11-52. In Yamagata Prefectural Museum (ed), Report on Fossil Cetacea from the Pliocene, Noguchi Formation of Mamurogawa Town, Yamagata Prefecture. Yamagata Prefectural Museum, Yamagata.

Nagasawa, K., Ooba, S., Abe, R., and Abe, H. 2002. Cetacean fossils from the Neogene, the Akamatsu River, Okura Village, Mogami District, Yamagata Prefecture. Applied Geology of Yamagata, 22:52-57.

Nagasawa, K., Ooba, S., Abe, R., Abe, H., and Ogasawara, K. 2009. A physeteriid tooth from the Akamatsu River, Okura Village, Yamagata Prefecture. Applied Geology of Yamagata, 29:57-60.

Nakamura, G. and Kato, H. 2014. Developmental changes in the skull morphology of common minke whales Balaenoptera acutorostrata. Journal of Morphology, 275:1113-1121. https:// doi.org/10.1002/jmor.20288

Nakamura, G., Kato, H., and Fujise, Y. 2012. Relative growth of the skull of the common minke whale Balaenoptera acutorostrata from the North Pacific in comparison to other Balaenoptera species. Mammal Study, 37:105-112. https://doi.org/10.3106/041.037.0201

Oishi, M. 1994. Cervical vertebrae of a fossil balaenopterid whale from the lower Pliocene strata in Ichinoseki City, Iwate Prefecture, Northeast Japan. Monograph of the Association of Geological Collaborators Japan, 43:111-122.

Oishi, M. 1987. Pliocene baleen whales and large sea lion from Ichinoseki and Hiraizumi area, Iwate Prefecture, Japan. Bulletin of the Iwate Prefectural Museum, 5:85-98.

Oishi, M. 1988. Fossil mysticetes from the Pliocene strata in the southernpart of Iwate Prefecture, p. 35-41. In Hasegawa, Y. (ed), Studies on the Fossil Marine Mammals from Japan. The Grant-in-Aid for Scientific Research from the Ministry of Education, Science and Culture, Yokohama.

Oishi, M. 1997. A dentary of Sibbaldus sp. from the lower Pliocene of Hiraizumi, Iwate Prefecture, northeast Japan. Bulletin of the Iwate Prefectural Museum, 15:1-10.

Oishi, M. and Hasegawa, Y. 1995a. A list of fossil cetaceans in Japan. Island Arc, 3(4):493-505.

Oishi, M. and Hasegawa, Y. 1995b. Diversity of Pliocene mysticetes from eastern Japan. Island Arc, 3(4):436-452. 
Oishi, M., Ono, K., Kawakami, T., Sato, J., Nokariya, H., and Hasegawa, Y. 1985. Pliocene baleen whales and bony-toothed bird from Iwate Prefecture, Japan (Parts 1-6). Bulletin of the Iwate Prefectural Museum, 3:143-162.

Perrin, W.F. 1975. Variation of spotted and spinner porpoise (Genus, Stenella) in the eastern Pacific and Hawaii. Bulletin of the Scripps Institution of Oceanography, 21:1-206.

Pilleri, G. 1989. Balaenoptera siberi, ein neuer spatmiozaner bartenwal aus der Pisco-formation Perus, p. 65-84. In Pilleri, G. (ed), Beitrage zur Palaontologie der Cetaceen Perus. Bern.

Sacco, F. 1890. Sopra una mandibola di balaenoptera dell'Astigiana. Carlo Clausen.

Sato, T., Sato, M., Kobayashi, S., and Aizu Fossil Research Group. 2010. A fossil balaenopterid whale from the Upper Miocene Shiotsubo Formation in Takasato, Kitakata City, Fukushima Prefecture, northeast Japan. Earth Science (Chikyu Kagaku), 64:23-28. https://doi.org/ 10.15080/agcjchikyukagaku.64.1_23

Strobel, P. 1881. Iconografia comparata delle ossa fossili del gabinetto di storia naturale dell'Università di Parma. L. Battei. https://doi.org/0.5962/bhl.title.60846

Tamiya, R. and Applied Geological Society of Yamagata. 2016. Geological Map of Yamagata Prefecture, 1:100000, the Mogami District. Yamagata University Press, Prefecture.

Tanaka, Y. 2016. A new and ontogenetically younger specimen of Numataphocoena yamashitai from the lower Pliocene, the upper part of the Horokaoshirarika Formation, Numata, Hokkaido, Japan. Paleontological Research, 20:105-115. https://doi.org/10.2517/ 2015PR026

Tanaka, Y. and Ichishima, H. 2016. A new skull of the fossil porpoise Numataphocoena yamashitai (Cetacea: Phocoenidae) from the upper part of the Horokaoshirarika Formation (lower Pliocene), Numata Town, Hokkaido, Japan, and its phylogenetic position. Palaeontologia Electronica, 19.3.49A:1-28. https://doi.org/10.26879/663 palaeo-electronica.org/content/2016/1663-a-new-skull-of-numataphocoena

Tanaka, Y. and Taruno, H. 2017. Balaenoptera edeni skull from the Holocene (Quaternary) of Osaka City, Japan. Palaeontologia Electronica, 20.3.50A:1-13. https://doi.org/10.26879/785 palaeo-electronica.org/content/2017/2025-a-japanese-holocene-whale

Tanaka, Y. and Watanabe, M. 2019a. An early and new member of the Balaenopteridae from the upper Miocene of Hokkaido, Japan. Journal of Systematic Palaeontology, 17(16):1417-1431. https://doi.org/10.1080/14772019.2018.1532968

Tanaka, Y. and Watanabe, M. 2019b. A geologically old and ontogenetically young Herpetocetus $\mathrm{sp}$. from the late Miocene of Hokkaido, Japan. Journal of Vertebrate Paleontology, 38:1-10. https://doi.org/10.1080/02724634.2018.1478842

Tsai, C.H. and Fordyce, R.E. 2014. Juvenile morphology in baleen whale phylogeny. Naturwissenschaften, 101:765-769. https://doi.org/10.1007/s00114-014-1216-9

Tsai, C.H. and Fordyce, R.E. 2016. Archaic baleen whale from the Kokoamu Greensand: earbones distinguish a new late Oligocene mysticete (Cetacea: Mysticeti) from New Zealand. Journal of the Royal Society of New Zealand, 46:1-22. https://doi.org/10.1080/ 03036758.2016.1156552

Uhen, M.D. 2004. Form, function, and anatomy of Dorudon atrox (Mammalia, Cetacea): an archaeocete from the middle to late Eocene of Egypt. University of Michigan Papers on Paleontology, 34:1-222.

Van Beneden, P.J. 1880. Les mysticetes a courts fanons des sables des environs d'anvers. Bulletins de L'Academie Royale des Sciences, des Lettres et des Beaux-Arts de Belgique, 2:11-27.

Walsh, B.M. and Berta, A. 2011. Occipital ossification of balaenopteroid mysticetes. The Anatomical Record, 294:391-398. https://doi.org/10.1002/ar.21340

Whitmore, F.C. and Kaltenbach, J.A. 2008. Neogene Cetacea of the Lee Creek Phosphate Mine, North Carolina. Virginia Museum of Natural History Special Publication, 14:181-269.

Zeigler, C.V., Chan, G.L., and Barnes, L.G. 1997. A new Late Miocene balaenopterid whale (Cetacea: Mysticeti), Parabalaenoptera baulinensis (new genus and species) from the Santa Cruz Mudstone, Point Reyes Peninsula, California. Proceedings of the California Academy of Sciences, 50:115-138. 


\section{APPENDIX 1}

Data matrix in NEXUS format. (Files for Appendix 1 and 2 available online as zipped file at https:/ /palaeo-electronica.org/content/2020/2943-fossil-rorqual-from-japan.)

\section{APPENDIX 2}

Data matrix in TNT format. (Files for Appendix 1 and 2 available online as zipped file at https:// palaeo-electronica.org/content/2020/2943-fossil-rorqual-from-japan.)

\section{APPENDIX 3}

\section{S3. Character list}

1. Length of rostral portion of maxilla anterior to antorbital notch less than bizygomatic width (0); equal to or greater than bizygomatic width (1); more than one and a half times the bizygomatic width (2).

2. Portion of rostrum anterior to nasals in lateral view below the level of the supraoccipital (0); raised to or above the supraoccipital (1).

3. Lateral edge of maxilla in cross section forms an angle of more than 45 degrees (0); lateral edge is flattened with an angle of less than 45 degrees (1).

4. Lateral border of maxilla anterior to antorbital notch or homologous point on rostrum in dorsal view concave (0); straight or slightly convex (1); broadly convex (2).

5. Transverse width of maxilla at midpoint distinctly less than that of the premaxilla (0); roughly equal to or up to twice the width of the premaxilla (1); more than twice the width of the premaxilla (2).

6. Premaxilla in dorsal view widens at anterior end (0); portion anterior to nasal opening narrows or remains the same width anteriorly (1).

7. Premaxilla adjacent to and anterior to narial fossa elevated above the maxilla and forming a distinct lateral face (0); continuous or nearly continuous with the maxilla (1).

8. Premaxilla adjacent to and at posterior edge of nasal opening does not clearly overhang maxilla (0); premaxilla overhangs maxilla (1).

9. Anterior portions of premaxillae firmly contact each other (0); premaxillae are separated or only loosely contact along their entire length (1).

10 . Suture between maxilla and premaxilla on rostrum firmly articulated (0); loose (1).

11. Antorbital process absent (0); present and defined by a steep face clearly separating the posterolateral corner of the maxilla from its more anterior rostral portion (1); present as a distinct anterior projection lateral to antorbital notch (2).
12. Anterior border of supraorbital process lateral to ascending process of the maxilla bordered by lacrimal and maxilla (0); bordered by lacrimal only (1); as state 0 but with the antorbital process of the maxilla and the anterior border of the supraorbital process separated by a basin (2); as state 0 but with the maxilla overriding the anteriormost border of the supraorbital process (3).

13. Distinct pocket between the ascending process of the maxilla dorsally and the supraorbital process ventrally absent (0); present (1).

14. Lateral process of maxilla absent (0); present and clearly distinct from ascending process of maxilla (1); present and confluent with ascending process of maxilla (2).

15. Posterior portion of palatal surface of maxilla flattened or slightly concave (0); medial portion of maxilla forms a longitudinal keel bordered laterally by a shallow longitudinal trough (1); medial portion forms a keel without any adjacent trough (2).

16. Palatal surface of anterior part of rostrum flat or gently concave (0); bears a pronounced longitudinal keel formed by the vomer and the medial edges of the maxillae (1).

17. Exposure of premaxilla on palate exposed along at least one third of the medial border of the maxilla (0); limited in extent to less than one third of the medial border of the maxilla (1).

18. Palatal window exposing vomer absent (0); present (1); narrow and variable exposure of vomer along most or all of the midline of the rostrum (2); vomer broadly exposed along the midline of the rostrum (3).

19. Palatal nutrient foramina and sulci absent (0); present (1).

20. Outline of suture between maxillae and palatines roughly straight transversely or bowed anteriorly (0); forms a posteriorly pointing $\mathrm{V}$ shape (1); anterior margins of palatines form two separate and posteriorly pointing $U$ shapes (2). 
21. Anteriormost point of palatine located in line with or posterior to the level of the antorbital notch or equivalent point on rostrum (0); located anterior to the level of the antorbital notch (1).

22. Anterior portion of palatine distinctly concave transversely and forming a sharp median crest absent (0); present (1).

23. Anterior edge of narial fossa located in posterior three quarters of rostrum (0); located in anterior quarter of rostrum (1).

24. Facial portion of rostrum in lateral view steplike (0); straight (1); concave (2).

25. Rostrum shape width at antorbital notches or equivalent point on rostrum less than $80 \%$ the length of the rostrum as measured from its tip to the antorbital notches (0); width at antorbital notches or equivalent point more than $80 \%$ the length of the rostrum (1).

26 . Teeth in adult individuals present (0); absent or vestigial (1).

27. Upper dentition comprises 10 teeth including M2 (0); includes 11 teeth including M3 or is polydont (1).

28. Large diastemata between posterior upper cheek teeth absent (0); present (1).

29. Enamel ornamentation on premolars vertical striations present on lingual surface only (0); heavy vertical striations present on both lingual and labial surfaces (1); vertical striations are poorly developed or absent (2); enamel is absent (3).

30. Shape of upper molars in lingual or labial view crown base distinctly wider than crown height (0); crown base is shorter than or roughly equal to crown height (1).

31. Ectocingulum on P3 and P4 present (0); absent (1).

32. Entocingulum on P3 and P4 present (0); absent (1).

33. Proximal portions of posterior upper premolar and molar roots separate along their entire length (0); fused proximally but separate distally (1); fused or closely apposed along their entire length (2).

34. Posteriormost upper tooth situated below anterior portion of orbit (0); situated anterior to anterior border of orbit (1).

35 . Heavy planar wear resulting in loss of most or all of tooth crown absent (0); present (1).

36. Outline of upper premolar crowns in anterior view straight (0); curved with the apex pointing ventrally (1).

37 . Heterodonty present with accessory denticles being well developed (0); absent or greatly reduced with accessory denticles absent or tiny compared to main cusp (1).
38. Skull length about one third of total body length absent (0); present (1).

39. Cranial asymmetry present (0); absent (1).

40. Diameter of orbit as measured between the distalmost points of the preorbital and postorbital processes less than $25 \%$ of bizygomatic width (0); $25 \%$ or more (1).

41. Anterior edge of supraorbital process lateral to ascending process of maxilla oriented transversely or pointing anteriorly (0); pointing posteriorly (1); linguiform and tapering to a point (2).

42. Outline of anterior edge of supraorbital process in dorsal view roughly straight or concave (0); distinctly sinusoidal (1).

43. Transverse width of anterior edge of supraorbital process lateral to ascending process of maxilla longer than or equal to the combined transverse width of the adjacent rostral bones as measured from the sagittal plane to the lateral border of the ascending process of the maxilla (0); shorter than the combined transverse width of the adjacent rostral bones (1).

44. Posterior border of supraorbital process in dorsal view concave (0); straight (1).

45. Supraorbital process of frontal in anterior view horizontal or nearly horizontal (0); gradually slopes away lateroventrally from the skull vertex (1); as state 1 but with the lateral portion of the supraorbital being nearly horizontal thus causing the latter to appear concave in anterior view (2); abruptly depressed to a level noticeably below the vertex with the lateral skull wall above the supraorbital formed by both parietal and frontal (3).

46. Anterior and posterior borders of supraorbital process in dorsal view roughly parallel or converging medially (0); converging laterally (1).

47. Width of supraorbital process as measured in a straight line from the lateralmost point of the postorbital process to the intertemporal constriction equal to or shorter than the anteroposterior length of the supraorbital process above the orbit (0); up to twice the length above the orbit (1); more than twice the length above the orbit (2).

48. Postorbital process in dorsal view oriented posteriorly (0); oriented laterally (1); oriented posterolaterally (2); short and not markedly projecting in any direction (3).

49. Postorbital process in lateral view pointed or rounded (0); forms and anteroposteriorly elongate triangle with a flattened posterior face (1).

50. Orbital rim of supraorbital process of frontal in lateral view dorsoventrally thin (0); thickened with a flat lateral surface (1); thickened with a rounded lateral surface (2). 
51. Position of anteriormost point of supraorbital process in dorsal view in line with the posterior extremity of the nasals or passing through the nasals (0); at the same level as the anterior extremity of the nasals (1); anterior to the anterior extremity of the nasals (2).

52. Dorsalmost point of orbit relative to lateral edge of rostrum in lateral view, with skull resting on a horizontal surface elevated above or roughly in line with the lateral edge of the rostrum (0); located well below the lateral edge of the rostrum (1).

53. Lacrimal in dorsal view situated entirely lateral to the ascending process of the maxilla (0); lacrimal extends medially and separates the lateral corner of the ascending process from the more anterior portion of the maxilla (1).

54. Contact of jugal with zygomatic process of squamosal the two bones overlap dorsoventrally (0); little or no overlap (1).

55. Anteriormost portion of jugal broadly underlapped by maxilla absent (0); present (1).

56. Optic canal in ventral view ventrally open (0); medial portion is enclosed by anterior and/or posterior bony laminae (1).

57. Postorbital ridge along medial portion of optic canal absent or anteroposteriorly thin, with the optic canal running adjacent to the posterior border of the supraorbital process (0); well developed and thickened, thus resulting in the displacement of the optic canal away from the posterior border of the supraorbital process (1).

58. Maxillary infraorbital plate absent (0); present (1).

59. Maxillary window originating from posterior border of infraorbital plate absent (0); present (1).

60 . Anteromedial corner of supraorbital process extending to a point medial to antorbital notch absent (0); present (1).

61. Preorbital region of frontal in lateral view thickened compared to more central portions of the orbit (0); dorsoventrally flat (1).

62. Enlarged dorsal infraorbital foramen on ascending process of maxilla, opening into a posterodorsally directed sulcus absent (0); present (1). 63. Premaxillary sac fossa absent (0); present (1). 64. Premaxillary foramen absent (0); present (1).

65. Suture between maxilla and frontal contact between the bones is straight or maxilla overrides anteromedial corner of the frontal (0); maxilla overrides half or more of the frontal (1).

66. Lateral borders of ascending process of maxilla lateral edges convergent with the process tapering to a point (0); lateral edges parallel or divergent posteriorly (1).
67. Posterior end of ascending process of premaxilla no contact with frontal or contacts the frontal with the posteriormost tip only (0); forms a robust contact with the frontal (1).

68. Triangular wedge of frontal separating ascending process of maxilla from nasal or premaxilla absent (0); present (1).

69. Posterior ends of ascending processes of maxillae in dorsal view separated by either frontals or both nasals and premaxillae (0); converging towards the midline and separated by nasals only (1); contact each other medially (2).

70. Relative position of posteriormost edge of ascending process of maxilla in dorsal view approximately in transverse line with or posterior to posterior edge of nasal (0); anterior to posterior edge of nasal (1).

71. Shape of posterior border of ascending process of maxilla pointed or rounded (0); squared off (1).

72. Lateral profile of cranium along exposure of parietals on vertex dorsal edge of parietal ascends steeply towards posterior edge of skull at an angle of 10 degrees or more measured relative to the lateral edge of rostrum (0); dorsal edge of parietal is low to flat with an angle of less than 10 degrees (1).

73. Length of nasal relative to bizygomatic width less than $50 \%$ of bizygomatic width (0); more than $50 \%$ of bizygomatic width (1).

74. Lateral margins of nasal parallel (0); posteriorly convergent (1).

75. Anterior margins of nasals roughly straight or $U$ shaped (0); form a distinct, posteriorly pointing $W$ shape (1); with point on midline and a gap on each side between premaxilla and nasal (2); form an anteriorly pointing W shape (3).

76. Dorsal surface of nasals flattened (0); developed into a sagittal keel (1).

77. Separation of posterior portions of nasals along sagittal plane by narial process of frontal present (0); absent (1).

78. Zygomatic process of squamosal and exoccipital in dorsal view clearly separated by an angle (0); posterior border of zygomatic process and lateral edge of exoccipital are confluent forming a continuous or nearly continuous lateral skull border (1).

79. Orbitotemporal crest positioned along posterior border of supraorbital process with the origin of the temporal muscle facing posteriorly or posteroventrally (0); absent or positioned on the dorsal surface of the supraorbital process with the origin of the temporal muscle facing posterodorsally or dorsally (1). 
80. Area enclosed by orbitotemporal crest on supraorbital process of frontal forms less than half of the dorsal surface of the supraorbital process (0); covers half or more of the dorsal surface of the supraorbital process (1).

81. Outline and orientation of orbitotemporal crest subparallel to posterior border of supraorbital process (0); distal half oriented distinctly posterolaterally and approaching the posterolateral corner of the supraorbital process (1); as state 1 but with the crest terminating halfway along the posterior border of the supraorbital process (2); as state 1 but with the crest being distinctly U-shaped (3).

82. Shape of temporal fossa longer anteroposteriorly than wide transversely or as wide as long (0); wider than long (1).

83. Intertemporal constriction longer anteroposteriorly than wide transversely (0); as state 1 but with the temporal fossa forming a large parasagittal oval (1); wider transversely than long anteroposteriorly (2).

84. Exposure of frontal on skull vertex broadly exposed (0); anteroposteriorly compressed or absent (1).

85. Parietal and interparietal anteriormost point located no further forward than postorbital process (0); anteriormost point in line with supraorbital process (1).

86. Outline of fronto-parietal suture straight or lobate (0); frontals projects posteriorly along the sagittal plane and separate the left and right parietal anteriorly (1); highly irregular (2).

87. Parietal in lateral view as long or longer anteroposteriorly than high dorsoventrally (0); higher dorsoventrally than long anteroposteriorly (1).

88. Spreading of anterolateral portion of parietal on to posteromedial corner of supraorbital process of frontal absent (0); present (1).

89. Anteriormost point of parietal and interparietal more posterior than the posterior border of the ascending process of the maxilla (0); more anterior than or in line with the posterior border of the ascending process of the maxilla (1).

90. Anteriormost point of supraoccipital in dorsal view located posterior to or in line with the anterior border of the squamosal fossa (0); in line with temporal fossa, but posterior to the apex of the zygomatic process of the squamosal (1); in line with or located anterior to the level of the apex of the zygomatic process of the squamosal (2); in line with the anterior half or anterior edge of the supraorbital process (3).
91. Anteroposterior position of posterior apex of nuchal crest posterior to the occipital condyle (0); anterior to or in line with the posteriormost point of the occipital condyle (1).

92. Mediolateral position of posterior apex of nuchal crest aligned with the medial half or halfway point of the temporal fossa (0); approaching the level of the lateral border of the temporal fossa (1). 93. Distinct nuchal tubercle at junction of parietosquamosal suture and supraoccipital absent (0); present (1).

94. Exposure of alisphenoid in or at ventral border of temporal fossa exposed on temporal wall of skull and contributing to orbital fissure (0); alisphenoid separated from orbital fissure or not exposed on temporal skull wall (1).

95. Postparietal foramen located at junction of parietal and squamosal absent (0); present (1).

96. Zygomatic process of squamosal extremely well developed and robust in dorsal view absent (0); present (1).

97. Zygomatic process of squamosal dorsoventrally expanded in lateral view absent (0); present with the zygomatic process being distinctly higher dorsoventrally than wide transversely (1).

98. Orientation of zygomatic process of squamosal in dorsal view directed anteromedially (0); directed anteriorly or slightly anterolaterally (1); directed anterolaterally (2).

99. Zygomatic process of squamosal in lateral or ventral view tapering anteriorly (0); expanded anteriorly, thus forming a central constriction (1).

100. Twisting of zygomatic process of squamosal absent (0); present with the zygomatic process being partially twisted clockwise on the left and anticlockwise on the right (1); as state 1 but with the process twisted almost 90 degrees (2).

101. Position of apex of zygomatic process of squamosal situated entirely posterior to the postorbital process (0); closely apposed to the postorbital process or situated ventral to the latter (1).

102. Apex of zygomatic process of squamosal deflected anteroventrally absent (0); present (1).

103. Supramastoid crest on entire zygomatic process present (0); absent (1).

104. Size of squamosal including zygomatic and postglenoid processes longer anteroposteriorly than high dorsoventrally or about as high as long (0); distinctly higher than long (1).

105. Parieto-squamosal suture shaped like a crest or ridge absent or low (0); present and distinctly elevated (1). 
106. Squamosal prominence present as a projection on the crest delimiting the lateral or posterolateral edge of the squamosal fossa (0); absent (1).

107. Transverse width of squamosal lateral to exoccipital width equal to or greater than $15 \%$ of the distance between the sagittal plane and the lateral edge of the exoccipital (0); exposed portion of squamosal is less than $15 \%$ of that distance (1).

108. Length of squamosal fossa relative to maximum transverse width of temporal fossa as measured in a straight line from the posteriormost point of the temporal fossa to the posteriormost point of the nuchal crest length of squamosal fossa is three quarters the width of the temporal fossa or longer (0); length of squamosal fossa is less than three quarters the width of the temporal fossa (1).

109. Squamosal cleft absent (0); present (1).

110. Squamosal crease absent (0); present (1).

111. Paired tubercles on supraoccipital absent (0); limited to low ridges forming the lateral edges of $a$ medial fossa (1); present (2).

112. Lateral edge of supraoccipital in dorsal view convex (0); straight (1); concave (2); sigmoidal (3).

113. Anterior border of supraoccipital shield rounded or pointed (0); squared (1).

114. Overall outline of supraoccipital in dorsal view rounded (0); triangular (1).

115. Anterior half of dorsal surface of supraoccipital concave (0); flat or convex (1).

116. External occipital crest absent or faint (0); restricted to anterior half of supraoccipital shield (1); present and running all the way along the supraoccipital shield (2).

117. Tip of postglenoid process in lateral view curving anteriorly (0); pointing ventrally (1); pointing posteriorly (2).

118. Ventral edge of postglenoid process in lateral view approximately in line with or dorsal to ventral edge of exoccipital (0); extending well ventral to ventral edge of exoccipital (1).

119. Orientation of postglenoid process in posterior view ventrolateral (0); ventral (1); ventromedial (2).

120. Outline of postglenoid process in anterior or posterior view parabolic (0); as state 0 but with lateral and medial edges parallel or concave (1); as state 1 but distinctly wider transversely than high dorsoventrally (2); triangular (3); trapezoidal with a ventrally directed medial border (4).

121. Twisting of postglenoid process in ventral view absent (0); twisted clockwise on the left side and anticlockwise on the right side so that the glenoid cavity faces anteromedially (1).
122. Position of base of postglenoid process in ventral or posterior view in line with the lateral edge of the skull (0); shifted away medially from the lateral edge of the skull (1).

123. Medial border of postglenoid process in ventral view confluent with more medial portion of squamosal (0); offset from remainder of squamosal by a distinct ridge (1).

124. Choanal margin of palatine in ventral view absent (0); straight or convex (1); concave (2); forms a longitudinal notch (3).

125. Pterygoid in ventral view partially or entirely exposed (0); palatine almost completely covers pterygoid and extends on to the hamular process (1).

126. Anteriomost point of pterygoid sinus fossa located anterior to foramen pseudovale (0); approximately in line with anterior edge of foramen pseudovale (1); located posterior to anterior edge of foramen pseudovale (2).

127. Superior/lateral lamina of pterygoid located entirely anterior to the anterior process of the periotic (0); extending on to the anterior process of the periotic (1).

128. Shape of pterygoid hamulus finger-like (0); expanded into a dorsoventrally flattened plate flooring the pterygoid sinus fossa (1); triangular and wing-like (2); reduced in size or almost absent (3).

129. Position of pterygoid hamuli in ventral view located directly adjacent to the sagittal plane and almost contacting each other (0); well separated from each other (1).

130. Position of foramen pseudovale foramen located within squamosal or between squamosal and pterygoid and opening anterolaterally or laterally (0); as state 0 but with foramen opening posteriorly (1); foramen lies within pterygoid (2).

131. Foramen pseudovale raised above more lateral portions of squamosal in ventral view absent (0); present (1).

132. Fossa on squamosal for reception of sigmoid process of tympanic bulla present (0); absent or poorly defined (1).

133. Base of postglenoid process in ventral view in transverse line with or located posterior to the posterior half of the tympanic bulla (0); in transverse line with the anteroposterior centre of the tympanic bulla (1); in transverse line with or located anterior to the anterior half of the tympanic bulla (2).

134. Ventral border of sagittal part of vomer (nasal septum) in ventral view posteriormost portion projects beyond the posterior border of the palatines 
and is visible in ventral view (0); completely covered by palatines (1).

135. Basioccipital crest narrow transversely (0); wide and bulbous (1).

136. Lateral border of basioccipital crest in ventral view straight (0); concave (1).

137. Orientation of basioccipital crests in ventral view diverging posteriorly (0); parallel or subparallel with no angle formed (1).

138. Ventromedial corner of paroccipital process in posterior view located more ventrally than the basioccipital crest (0); level with or more dorsal than the basioccipital crest (1).

139. Posteriormost point of exoccipital in dorsal view located more anteriorly than posterior edge of occipital condyle (0); level with or posterior to posterior edge of condyle (1).

140. Outline of stylohyal in cross section cylindrical (0); flattened (1).

141. Orientation of thyrohyal in dorsal or ventral view oriented posteriorly (0); oriented laterally (1).

142. Shape of thyrohyal cylindrical (0); flattened and wing-like (1); plate-like (2).

143. Ankylosed basihyal and thyrohyals absent (0); present (1).

144. Dorsal and medial elongation of pars cochlearis towards cranial cavity absent (0); present (1); as state 1 , but with only the anterior side of the pars cochlearis being elongated (2).

145. Attachment of anterior process to pars cochlearis absent (0); present (1).

146. Anterior process of periotic in lateral view squared off or rounded (0); triangular (1); anterior border of process is two-bladed and L-shaped (2).

147. Shape of anteroventral angle of anterior process of periotic in medial or lateral view rounded or forms a relatively blunt angle (0); slender and tapering to a point (1).

148. Ventral edge of anterior process of periotic in medial view at the same level or dorsal to ventral edge of pars cochlearis (0); ventral to ventral profile of pars cochlearis (1).

149. Dorsal deflection of anterodorsal corner of anterior process absent (0); present (1).

150. Anterior process transversely compressed and blade-like absent (0); present (1).

151. Length of anterior process of periotic shorter than the anteroposterior length of the pars cochlearis, as measured from the anterior border of the pars cochlearis to the medial border of the fenestra rotunda (0); same length or longer than the pars cochlearis (1).

152. Anteroexternal sulcus forms an oblique or vertical groove on lateral side of anterior process, immediately anterior to lateral tuberosity (0); absent (1).

153. Pyramidal process absent (0); present (1).

154. Articulation of anterior process of periotic and tympanic bulla accessory ossicle of tympanic bulla contacts fovea epitubaria on the anterior process of the periotic (0); accessory ossicle fused to periotic but still clearly defined anteriorly (1); accessory ossicle or homologous region fused to periotic (2). 155. Anterior bullar facet present (0); absent (1).

156. Lateral tuberosity of anterior process absent or relatively small and rounded (0); well-developed and distinctly triangular (1); hypertrophied and blade-like (2); forms a distinct shelf (3).

157. Position of lateral tuberosity situated posterolateral to anterior pedicle of tympanic bulla or fovea epitubaria (0); situated lateral or anterolateral to anterior pedicle of tympanic bulla or fovea epitubaria (1).

158. Body of periotic lateral to pars cochlearis hypertrophied absent (0); present laterally and ventrally (1); present laterally only (2).

159. Mallear fossa well excavated and possessing a clearly defined rim (0); present only as a depression with diffuse edges (1).

160. Distinct ridge delimiting insertion surface of tensor tympani on medial side of anterior process absent (0); absent but insertion surface distinctly excavated (1); present (2).

161. Dorsal extension of attachment area for tensor tympani on medial side of anterior process absent or indistinct (0); present as a deeply excavated canal (1).

162. Anteromedial corner of pars cochlearis in ventral view developed as a rounded, anteroposterior ridge (0); angular and projecting medially (1); smooth and rounded (2).

163. Promontorial groove on medial side of pars cochlearis present, but relatively shallow (0); present and deeply excavated (1); present and forming a distinct constriction, separating a smooth and rounded ventral portion of the pars cochlearis from a flattened and striated dorsal one (2); absent (3).

164. Caudal tympanic process in posteromedial view well separated from crista parotica (0); narrow separation or contact (1).

165. Posteromedial corner of pars cochlearis medial to fenestra rotunda rounded and level with fenestra rotunda (0); inflated and projecting posteriorly beyond fenestra rotunda (1).

166. Morphology of caudal tympanic process developed as a posteriorly extending triangular shelf (0); as state 0 , but with the ventral border bulging ventrally (1); as state 0 , but pointing pos- 
terodorsally (2); developed as a robust, ventrally directed projection (3); absent or poorly developed (4).

167. Elongate lobe and fossa extending posteromedially from fenestra ovalis in ventral view absent (0); present (1).

168. Anteroposterior alignment of proximal opening of facial canal, internal acoustic meatus and aperture for cochlear aqueduct present (0); absent (1).

169. Anteroposterior alignment of aperture for cochlear aqueduct and aperture for vestibular aqueduct absent (0); present (1).

170. Prominent septum dividing foramina for vestibular and cochlear nerves within internal acoustic meatus present (0); absent (1).

171. Shape of aperture for cochlear aqueduct round with sharply defined dorsal margins (0); slitlike (1).

172. Size of aperture for cochlear aqueduct smaller than aperture for vestibular aqueduct (0); approximately the same size (1).

173. Aperture for cochlear aqueduct and fenestra rotunda separate (0); confluent (1).

174. Superior process present as a distinct crest forming the lateral wall of the suprameatal fossa (0); the lateral border of the suprameatal fossa is low and not clearly defined (1).

175. Suprameatal area hypertrophied absent (0); present (1).

176. Development of crista transversa depressed well below the rim of the internal acoustic meatus (0); well developed and reaching the cerebral surface of the pars cochlearis (1).

177. Morphology of crista transversa developed as a septum of varying thickness (0); proximal opening of facial canal is widely separated from internal acoustic meatus and connected to the latter via a distinct sulcus (1).

178. Hiatus Fallopii absent or small opening located anterior or anteroventral to proximal opening of facial canal (0); as state 0 , but with the hiatus Fallopii being well developed and large (1); anterior border of proximal opening of facial canal is continuous with the hiatus Fallopii and shaped like a fissure (2).

179. Size of proximal opening of facial canal no more than half the size of the internal acoustic meatus (0); more than half the size of the internal acoustic meatus (1).

180. Squamosal flange located posterior to lateral tuberosity absent (0); present (1).
181. Articulation surfaces on posterior processes of tympanic bulla and periotic unfused (0); fused in adults to form compound posterior process (1).

182. Facial sulcus on compound posterior process ventrally open (0); partially or entirely floored by a posteroventral flange (1); as state 1 , but with the posteroventral flange being markedly enlarged (2). 183. Position of facial sulcus on compound posterior process in ventral view facial sulcus is posteriorly open and runs close to or along the posterior border of the compound posterior process (0); facial sulcus located centrally on the ventral surface of the compound posterior process and posteriorly bounded by a distinct ridge (1).

184. Orientation of compound posterior process in ventral view, with periotic being in situ oriented posterolaterally with respect to the longitudinal axis of the anterior process of the periotic (0); oriented at a right angle to the axis of the anterior process (1).

185. Shape of compound posterior process cylindrical or slightly conical (0); short and stocky (1); flattened anteroposteriorly (2); forms a distinct plug (3).

186. Exposure of compound posterior process on lateral skull wall external surface of compound posterior process is absent or poorly defined (0); external surface is present but distinct from lateral skull wall (1); external surface is expanded and firmly integrated into the lateral skull wall (2); as state 2, but with the external surface of the compound posterior process being concave and defined by a distinct ridge separating it from the ventral surface (3). 187 . Bony texture of ventral surface of compound posterior process massive (0); fibrous (1).

188. Neck of compound posterior process markedly constricted absent (0); present (1).

189. Anterior border of bulla in dorsal or ventral view obliquely truncated (0); squared (1); rounded (2); pointed (3).

190. Anterior portion of bulla transversely wider than posterior portion in ventral view absent $(0)$; present (1).

191. In situ orientation of main axes of tympanic bullae in ventral view diverging posteriorly (0); parallel (1); diverging anteriorly (2).

192. Position of dorsal origin of lateral furrow located along posterior two thirds of the anteroposterior length of the bulla (0); located at roughly one third of the anteroposterior length of the bulla (1).

193. Orientation of lateral furrow in lateral view ventral (0); distinctly anteroventral (1). 
194. Orientation of ventral keel of lateral lobe of bulla faces ventrally (0); faces ventromedially or medially (1).

195. Anteroposterior outline of lateral lobe or main ridge of bulla concave (0); straight or convex (1).

196. Position of involucral ridge in dorsal view coincident with medial edge of the bulla (0); laterally retracted (1).

197. Sigmoid process deflected laterally in anterior or posterior view absent (0); present (1); as state 1, but with the sigmoid process being nearly horizontal (2).

198. Dorsomedial corner of sigmoid process in anterior view separated from the pedicle of the malleus (0); confluent with the pedicle of the malleus (1).

199. Ventral margin of sigmoid process in lateral view present (0); absent, with the lateral margin of the sigmoid process turning smoothly into a sulcus on the lateral side of the bulla (1).

200. Shape of conical process in lateral view well developed and dorsally convex (0); reduced to a low ridge or absent (1).

201. Elliptical foramen present (0); absent (1).

202. Medial lobe of tympanic bulla present as distinct lobe and transversely wider than its lateral counterpart (0); present but subequal in width to the lateral lobe or smaller (1); absent or indistinct (2).

203. Crest connecting medial and lateral lobes of tympanic bulla in posterior view present (0); absent (1).

204. Anteriormost point of involucral ridge extends anteriorly to form the anteriormost point of the bulla (0); in line with or posterior to the anterior border of the bulla (1).

205. Dorsolateral surface of involucrum divided into a low anterior and an elevated posterior portion, separated by a clearly defined step (0); forms a continuous rim (1).

206. Transverse creases on dorsal surface of involucrum poorly developed or absent (0); well defined and deep (1).

207. Ridge on inside of bulla extends laterally from involucrum and partially divides cavum tympani into anterior and posterior portions (0); absent (1).

208. Development of tympanic sulcus developed as a faint line (0); forms a distinct crest or sulcus (1).

209. Outline and position of tympanic sulcus forms a semicircular and ventrally curved line well separated from the intersection of the conical and sigmoid processes (0); forms a roughly horizontal line at or close to the level of the intersection of the conical and sigmoid processes (1).

210. Anteromedial portion of ventral surface of tympanic bulla transversely convex (0); distinctly flattened or slightly concave (1).

211. Anterolateral corner of bulla broadly rounded $(0)$; inflated and forming a distinct lobe (1); flattened (2).

212. Anterolateral ridge or shelf absent (0); present (1).

213. Position of posterior pedicle of tympanic bulla in dorsal view situated at or near the posterior border of the bulla (0); located far anterior to the posterior end of the bulla (1).

214. Posterior mandibular cheek teeth oriented vertically or anteriorly (0); reclined posteriorly (1).

215. Medial surface of central part of mandible similar to lateral surface (0); distinctly flattened relative to lateral surface (1).

216. Dorsomedial surface of posterior portion of mandibular body flat or convex (0); distinctly excavated (1).

217. Mandibular symphysis sutured or fused (0); unsutured (1).

218. Outline of posterior portion of mandible in dorsal or ventral view follows a straight line or simple curve (0); sigmoidal owing to a laterally reflexed neck and condyle (1).

219. Mandibular body in dorsal view bowed medially (0); straight (1); bowed laterally, but with curvature mainly confined to anterior portion of mandible (2); evenly bowed laterally (3).

220. Anterior extremity of mandible vertical or slightly twisted, with the ventral edge shifted medially (0); apex of mandible shifted to an almost horizontal position (1).

221. Mandibular body in medial or lateral view height of ramus remains roughly constant throughout (0); arched dorsally (1); increases in height anteroposteriorly (2); dorsoventrally constricted near the centre (3); decreasing in height anteroposteriorly, with the anteriormost portion being distinctly expanded (4).

222. Height of mandibular foramen dorsoventral height approximately that of the horizontal ramus, thus forming a mandibular fossa (0); dorsoventral height about half that of the horizontal ramus or less (1).

223. Anterior border of mandibular foramen rounded (0); sharply triangular (1).

224. Dorsal border of mandibular foramen projected medially and developed into a roof absent (0); present (1). 
225. Satellite process absent or limited to a low rugosity (0); present (1).

226. Ridge on posteromedial portion of coronoid process running close and parallel to its posterior border absent (0); present (1).

227. Relative position of anterior border of mandibular foramen in line with coronoid process (0); posterior to coronoid process (1).

228. Subcondylar furrow absent or extremely shallow (0); present as a well-defined groove medially only (1); as state 1 , but with the dorsal border of the furrow being accentuated by a medially welldeveloped condyle (2); extends across the posterior surface of the condyle, separating it from the angular process both medially and laterally (3).

229. Coronoid process in lateral or medial view forms a broad plate (0); distinctly triangular (1); shaped like a finger and pointing posteriorly (2).

230. Shape of coronoid process (if triangular) in lateral or medial view sharply triangular and about as high dorsoventrally as long anteroposteriorly (0); bluntly triangular and considerably longer than high (1).

231. Anterior outline of coronoid process vertical (0); bent laterally (1).

232. Postcoronoid elevation absent (0); present (1).

233. Development of angular process in medial view hollowed out (0); robust (1).

234. Anteroposterior position of angular process located below the condyle, or slightly anterior (0); projects posteriorly beyond the condyle (1).

235. Angular process deflected ventrally absent (0); present (1).

236. Fossa on medial side of angular process absent (0); present (1).

237. Orientation of articular surface of mandibular condyle posterior (0); posterodorsal (1); dorsal, with the condyle being confluent with a dorsoventrally expanded angular process (2); dorsal, with the condyle being larger than and clearly offset from the angular process (3).

238. Sulcus for attachment of mylohyoid muscle on ventromedial surface of mandible absent (0); present (1).

239. Height of transverse process of atlas at base more than half the height of the articular surface (0); equal to half the height of the articular surface or less (1).

240. Foramen transversarium in axis absent (0); present (1).

241. Development of parapophysis and diapophysis on axis in anterior or posterior view parapophysis considerably more robust than diapophysis (0); parapophysis and diapophysis are similar in size (1).

242. Cervical vertebrae separate (0); partially fused starting from the axis (1); completely fused (2).

243. Parapophysis on seventh cervical vertebra present (0); absent (1).

244. Centra of cervical vertebrae in anterior or posterior view rounded (0); squared (1).

245. Orientation of transverse processes of anterior lumbar vertebrae in anterior or posterior view oriented distinctly ventrolaterally (0); oriented slightly ventrolaterally or subhorizontally (1); oriented laterally and horizontally (2).

246. Outline of transverse processes of lumbar vertebrae in anterior or posterior view flattened or slightly thickened (0); robust and triangular, with a dorsoventrally thickened base reaching up to the ventral border of the neural arch (1).

247. Apices of neural spines of posterior thoracic and anterior lumbar vertebrae anteroposteriorly expanded and squared off absent (0); present (1).

248. Number of lumbar vertebrae more than 12 (0); 10 to 12 (1); fewer than 10 (2).

249. Metapophyses on posterior thoracic and anterior lumbar vertebrae in lateral view oriented dorsally (0); oriented anterodorsally or anteriorly (1).

250. Sternum composed of several bones (0); composed of one bone (1).

251. Posterior ribs transversely expanded absent (0); present (1).

252. Outline of central ribs in lateral view evenly curved (0); sigmoidal (1).

253. Proportions of scapula anteroposterior length of scapula approximately equals or is less than its maximum dorsoventral height (0); maximum anteroposterior length clearly exceeds its maximum dorsoventral height (1).

254. Coracoid process of scapula present (0); absent (1).

255. Acromion process of scapula present (0); absent (1).

256. Supraspinous fossa of scapula present (0); absent or nearly absent, with acromion process located near anterior edge of scapula (1).

257. Deltoid crest of humerus present as a distinct crest (0); absent or reduced to a variably developed rugosity (1).

258. Humerus longer than or roughly the same length as radius and ulna (0); distinctly shorter than radius and ulna (1).

259. Orientation of humeral head in medial or lateral view angled (0); vertical (1). 
260. Distal portion of humerus in medial or lateral view distal epiphysis narrower than shaft (0); distal epiphysis equal to or flared compared to shaft (1).

261. Articulation facet for radius on humerus in medial or lateral view radial and ulnar facets are subequal in size (0); radial facet is distinctly larger than ulnar facet, excluding the olecranon (1).

262 . Olecranon process present as a distinct process (0); absent (1).

263. Manus pentadactyl (0); tetradactyl (1).

264. Femur present as a relatively well-developed bone (0); absent or reduced to a barely recognisable lump with an extremely rough surface texture (1).

265. Tibia present (0); absent (1).

266. Ventral throat grooves absent (0); present and terminate well anterior to umbilicus (1); present and extend to umbilicus (2).
267. Ventral throat pouch absent (0); present (1).

268. Tongue muscular (0); reduced and predominantly connective tissue (1).

269. Temporomandibular joint synovial (0); fibrocartilagenous mass originates in the glenoid fossa and envelopes the mandibular condyle (1).

270 . Longitudinal ridges on rostrum absent or indistinct (0); single median ridge (1); three longitudinal ridges (2).

271. Dorsal fin present as fin or dorsal hump (0); absent (1).

272. Chromosome number 42 (0); 44 (1).

Newly added character

273. Lateral ridge of the fovea epitubaria blunt or no ridge (0);sharp and is at the center of the anterior process (1); sharp and is at the lateral part of the anterior process (2).

\section{APPENDIX 4}

\section{Modifications from the character list of Tanaka and Watanabe (2019a)}

78. Zygomatic process of squamosal and exoccipital in dorsal view clearly separated by an angle (0); posterior border of zygomatic process and lateral edge of exoccipital are confluent forming a continuous or nearly continuous lateral skull border (1). Miobalaenoptera numataensis (NFL 18) ? to 0

112. Lateral edge of supraoccipital in dorsal view convex (0); straight (1); concave (2); sigmoidal (3). Miobalaenoptera numataensis (NFL 18) 2 to ?
157. Position of lateral tuberosity situated posterolateral to anterior pedicle of tympanic bulla or fovea epitubaria (0); situated lateral or anterolateral to anterior pedicle of tympanic bulla or fovea epitubaria (1).

Miobalaenoptera numataensis (NFL 18) ? to 1

188. Neck of compound posterior process markedly constricted absent (0); present (1).

Taikicetus inouei 0 to 1 


\section{APPENDIX 5}

Full figure of the $50 \%$ majority consensus tree.

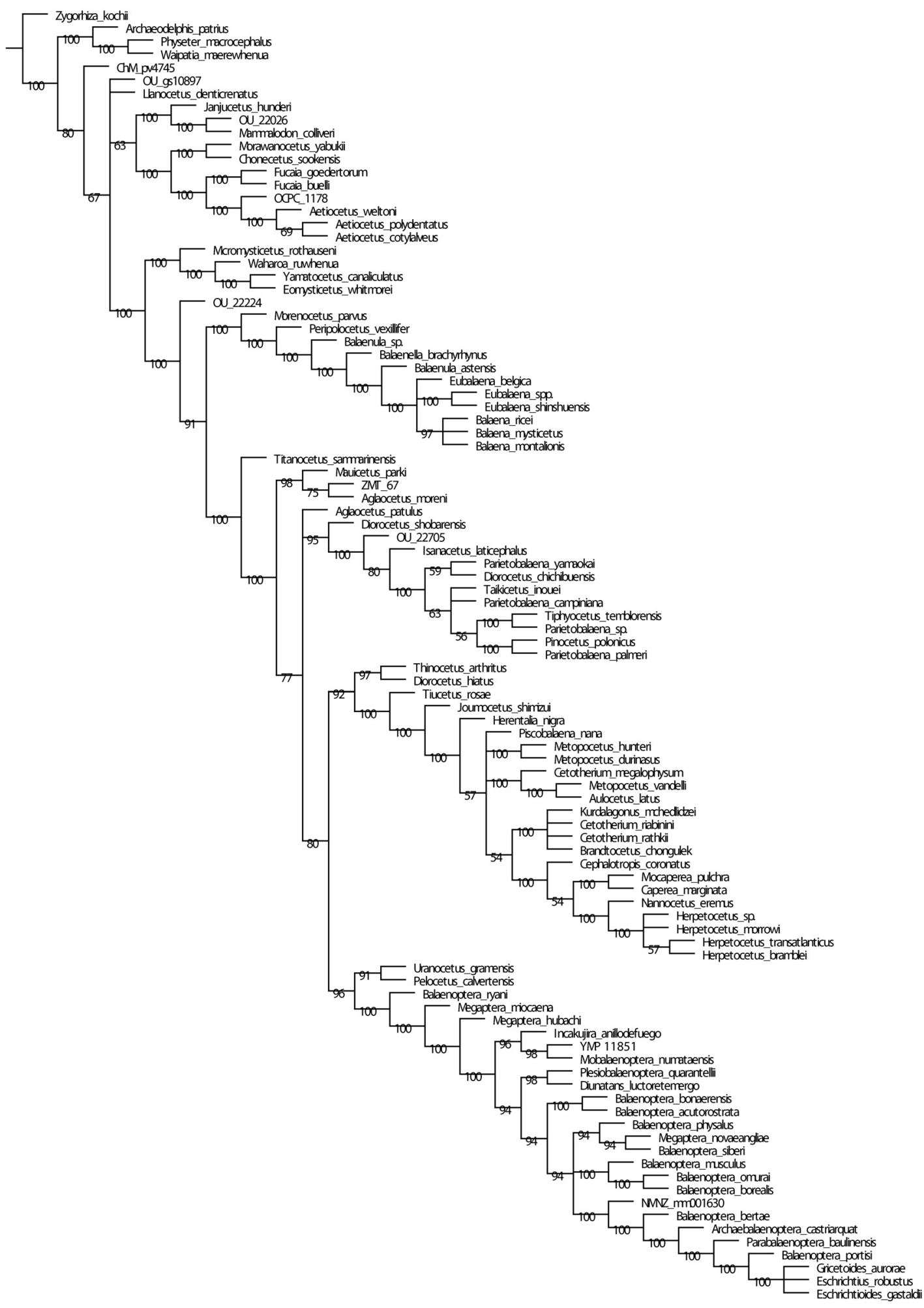

